\title{
XXI.
}

Aus dem Augustahospital in Breslau.

\section{Ueber das Cystadenoma mammae (Schimmelbusch) und seine Beziehungen zum Carcinom der Brustdrüse.}

\author{
Von \\ Privatdocenten Dr. Tietze, Bresliu. \\ (Mit 12 Abbildungen in Text und Tafel II.)
}

Durch die Arbeiten ron Sasse, Mintz, Maly und Roloff ') ist die Discussion über die Bedeutung des von Schimmelbusch sogenannten Cystadenoma mammae aufs neue beleht worden; der nachfolyende Beitrag zu der Frage dürfte daher erlaubt erscheinen.

Bekanntlich handelt es sich in diesem wissenschaftlichen Streit um Folgendes:

Die ron Schimmelbusch unter dem Namen Cystadenoma mammae vor mehreren Jahren (1890) beschriebene Krankheit [Naladie kystique von Reclus] (1890) ist nicht nur auf dem damaligen Chirurgeneongress der Gegenstand ciner lebhaften, von verschiedenen Meinungen beherrsehten Discussion geworden, sondern sie hat auch später noch, bis in die juingste Zeit hinein, eine Reihe von Controversen gnezeitigt. $\Lambda$ uf der einen Seite können wir Sehimmelbusch sellist nennen, als IJaupttriger der entgegengesetzten Insicht haben

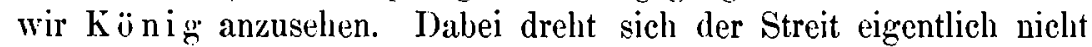
um die klinischen Erscheinungen und um den vorhandenen anatomischen Befund - so haben Schimmelbusch und ebenso König-(in seiner Mittleilung im Centralblatt für Chirurgie 1893) bereits Besehreibungen des Processes geliefert, welche auch von den späteren Bearbeitern dieses Themas nur unwesentlich ergïnzt worden sind als vichmehr um dic Frage, wie denn das Zustandekommen des anitomischen Bildes zu erklären und wie demnach das Wesen des Processes zu deuten sei.

1) Sasse, Langenbeck's Archir. Bd. LIV. - Il in tz, Berl. klin. Wochenschr. 1s!!!. - Il aly, Zeitschrift f. Heilkunde. Bd. XIX. 1s9s. - Roloff, IJentsche Zeitschrift f. Chirurgie. IBd. LAT, S. 106. 
Schimmelhusch schildert die Krankheit folgend(rmatssen: Das (ystadenoma mammae (maladie kystique) ist eine Erkrankmng, welche sich nicht selten bei weiblichen Individuen in mittleren Jalnen entwickelt, wanz wleichmässign Frauen und Personen befällt, die nicht geboren haben und welche zur Entwickelung zahlreicher crbsen- bis holınengrosser, selten wrösserer Cysten führt, die mit einer grrünlich bräunlichen, etwas klebrigen Flïssigkeit erfüllt sind und namentlich an der Hinterseite des Organes sich vorfinden. Die erkrankte Brustdrüse ist mit den Nachloarebebilden nicht verwachsen, die Erkrankuny befällt fast ausnahmslos beide Brüste zu grlcieher Zeit oder kurz nach einander. Mikroskopisch ist der Process dadurel gekennzeichnet, dafs sich eine starke Vermehrung der I)rüsenacini cinstellt, in welchen ausserden dic Ejithelien mächtigr, his zu cinem völligen Ausguss des Alreolus wuchern. Zwei und mehr benachbarte Alveolen können mitcinander verschmeizen, durch Zerfall des schlecht ernälırten Epithels der mittleren Sclichten entstehen die genannten Cysten der Ilamma, deren Fliissigkeit also eine Combination zwischen Secret und Zerfallsproducten darstellt. Das Bindegewebe der Mamma zeigt keine erhellichen entzündlichen oder proliferativen Vorgänge, dagegen erleidet es nicht selten eine Sklerosirung. Die Drüsen der Achsethöhle sind zuweilen, aber rein entzïndlich, geschwollen. Bekannt aber ist, lass auf dem Boden einer solehen Erkrankung cin Carcinom entstehen kann, unter 13 Fällen war 3 mal die Combination mit Carcinom rerzeichnet. Schimmelbusch hält für das Wesentliche des Processes eine primäre Wucherung des Epithels und sieht in demselben eine tumorartigre Bildung.

(iezen diesen Standpunkt hat, wie gesagt, sehr energisch König Terwahrungr eingelerwt. Ausser bei anderer, schon wenannter Gelewenheit, bezeichnet er auch in der neuesten Auflage seines Lelhrbuches dic $\Lambda$ uffassung ron Schimmelbusch als eine grundfalsche, weil dic klinische Erfahrung ganz zweifellos ergäbe, dass sich die fragliche Jirkrankung unter dem Bilde einer schubweis auftretenden Entzündung entwickele, unter der Forn entzündlicher Schwellungen, welche namentlich zur Zeit der Menstruation in die Erscheinung träten. Er hält den Process im Gegensatz zu Schimmelbusch für recht häufig, das milkroskopische Bild sehildert er ganz ähnlich wie dieser, betont aber (Centrallblatt), auch entzündliche Vorgänge im Bindegewebe beobachtet zu liaben. (ielıt der entzündliche Schub zurück, so schıwinden die infiltrirenden Zellen aus dem Bindegewebe, die Cysten vermögen sich durch Secretion ilırer Imnenwand zu vergrössern; schliess. lich kann auch ron der Ifand der Cyste der Eppithelbelag verschwinden, 
man hat nur einen serüsen Sack vor sich. In einer Anzalıl ron Erkrankungsherlen kommt es jedoch nicht zur Bildung grösserer Cysten. Die kleinen (ysten verschwinden, ilr Inhalt wird resorbirt, das Bindegewebe hingegen schrumpft, und an der erkrankten Partie der Driise bleibt cin lederartig harter wulstiger Iappen. $O b$ in der Drïse eine Wucherung des Gewebes im Sinne der physiologischen, während der Lactation stattfindenden Wucherung vor sich gehe, will $\mathrm{K}$ ̈̈nig nicht entscheiden, doch erinnerten manche Bilder daran. „IÏ̈chst ungewöhnlich“, fährt er fort (Lehrbuch) „und einer ganz anderen Krankheit, einer wirklichen Geschwulstentwickelung in der entzïndlich erkrankten Drüse angehörig, sind jene Veränderungen, welche dadurch entstehen, dass sich papilläre Epithelgeschwülste an der Innenfläehe der Cystenwand entwickeln, solche finden sich riel häufiger in dem wirklich cystischen Adenom der Drüse." - Kön ig bezeichnet, seiner Auffassung entsprechend, nit Vir chow das Cystadenom (Schimmelbusch) als Mastitis interstitialis circumscripta bezw. Mastitis chronica cystica. Auf dem König'schen Standpunkt steht auch Roloff in seiner jüngst publicirten Arbeit, d. h. auch er hält den Process für einen entziindlichen, er weist auch noch besonders darauf hin, dass ïhnliche Verïnderungen bei Carcinomen vorkommen und beschreibt eine Reilie typischer Befunde. Im übrigen weist Roloff, wie vor ihm sehon Sasse, darauf hin, dass das mikroskopische Bild des Cystadenoms kein gan\% einlreitliches ist. Fände man auch in dem iiberwiegenden Theil der erkrankten Brust genau die von Schimmelbusch gezeichneten Bilder, so gebe es doch auch Stellen, die anders aussähen, insofern als man ein Eindringen von Bindegewebe in den von erweiterten $\Lambda$ cinis gebildeten Raum constatiren könne. Entweder bemerke man dasselbe in Form feiner Maschen, die den Hohlraum durchzichen und die cinzelnen Zellcomplexe umspinnen, wobei bei gelegentlichem Ausfall derselben cin eigenthümlich wabenartiges Bild des Acinus entstiinde, oder man sehe schlanke, mit einem bindegewebigen Grundstock versehene l'apillen sich in das freie Iumen erheben. Andere Stellen trïgen zweifellos einen interstitiell entzündlichen Charakter.

Den klinischen Zusammenhang zwischen Cystadenom und Carcinom hatten schon fast alle anderen Beobachter constatirt, Schimmelbusch ebenso wie König; und bei der ersten Besprechung der Anrelegenheit vor dom Chirurgen-Congress hatte auch besonders II eidenhain darauf aufmerksam gemacht und er hatte einige Zweifel darüber geäussert, ob man iiberbau,t berechtigt sei, in der Jeobachtung. von Schimmelbusch eine Krankheit sui generis zu erblicken. 
Ëinen etwas vermittelnden Standpunkt in der ganzen Frage nimmt Sasse cin. Er hat ein ausserordentlich grosses Material von cystisehen Geschwïlsten aus der Bergmann'sehen Klinik untersncht und kommt dabei in Wesentlichen zu dem Ergebniss, dass thatsïchlich ein Theil der Cystenbildung der Mamma auf einem chronisch entzündlichen Process, dessen Zeichen deutlich auch im Bindegewebe nachweishar seien, heruhe; aber es besteht auch der von Schim melbusch beschriebene Process als typisches Kranklieitsbild zu Recht. Die Angabe von Schinm elbusch bedarf allerlings insofern einer Ergänzung, als die kleinen Jammacysten häufig cine Reihe zottiger papillärer Exerescenzen besitzen, wie sie Schim melbusch nicht gesehen hatte. Sasse schlägt statt des Namens Cystadenom den schon von anderer Seite benutzten eines Kystoms oder Polykystoms der Iamma vor. Streng unterscheidet er von diesem das intracanaliculäre Cystadenom, Welches darin besteht, dass in die Wand eines Musführungsyanges der Jamma ein alenomatöser Tumor hineinwuchert, welcher den Ausfiilurungsinang erweitert und eystisch gestaltet.

lis unterlient gar keinem Zweifel, dass die Arbeit von Sasse mit ihrem grossen, sorgfältig untersuchten Material cine besondere Bedeutung beansprucht, wenn ich auch den dusfïhrungen des Autors nicht in allen Punkten zu folgen rermag. So heisst es, glaube ich, den Standpunkt rerrïcken, wenn Sasse in seinen ,entzündlichen Cysten ${ }^{i 6}$ das Prototyp der von $\mathrm{K} \ddot{0} \mathrm{nig}$ angenommenen Mastitis interstitialis erblickt und scine Befunde mit der klinisehen Beschreibung des letzteren in Einklang zu bringen versucht. Diese rein entzïndlichen Formen ron Sasse unterscheiden sich nämlich mikroskopisch wesentlich rom Cystadenom ron Schimmelbusch und zwar schon dadureh, dass sie eine Erweiterungr der Ausfiihrungsgänge darstellen bei einer Auskleidung desselben mit einschichtigem Epithelbelag; solche Cysten hat aber $\mathrm{Köni} \ddot{n}$, wie doch aus seinen Beschreibungen hervorecht, gar nicht gemeint, sondern gerade die Schimmelbuschschen Cysten, die heschrcibt er, die deutet er aber anders wie dieser.

Dagegen bleibt es das Verlienst von Sasse, gezeigt zu hahen, dass, stehe man zu der Frage auch wie man wolle, die Existenz ciner zur Cystenbildung führenden chronischen interstitiellen Mastitis nicht zu bezwcifeln ist.

Ahgesehen von der durch rein interstitielle cntzündliche Vorgänge zur Cystenbildung führenden Mastitis nach Sasse habe ich wohl alle anderen zur Cystenbildung führenden Processe der Jamma an einem relativ grossen Mlaterial wiederholt beobachtet. Es ist nicht meine Absicht, ïber all diese verschiedenen Processe zu licrichten, viehmehr 
rerweise ich in dieser Richtung auf die Arbeit ron Sasse: ich will nur über zwei Affectionen im Folwenden sprechen, nämlich ïher das sogenante Cystadenom (Schimmelbusch) und das sogenannte intracanaliculäre Cystadenom (verol. Sasse) und zwar ist der \%weck der nachfolgenden Zeilen, darauf aufmerksam zn machen, wie eng diese rerschiedenen l'rocesse mit einander rerwandt sincl, so enc, dass man die strenge Seleidung, welche theils König, theils Sasse zwivchen den Cysten mit und ohne papillïre Erhebungen bezw. ardenomatöse Wucherungen aus der Wand machen, durehaus nicht aufrecht erhalten kann, 2. möchte ich, wie vor mir schon Viele, noch einmal ganz besonders den engen Zusammenhang zwischen den : nannten Fornen und den bösartigen Frkrankungen der Brustdrüise betonen und schliesslich wird es sich nicht umgehen lassen, in Kürze die Entstehung und Bedeutung des sogenannten Cystadenoms zu streifen.

Die im Folgenden zu besclureibenden Fälle zerfallen in zwei Gruplen, insofern sie sich einmal an das Bild des typischen (Yystidenom, das andere Mal an das Bild des Cystadenoma intracanaliculare (Sasse) anschlicssen.

$$
\text { Gruple A (Cystadenom). }
$$

Das Cystadenoma manmae (Sehjmmelbusch) habe ich als Assistent der chirurowischen Klinik in Breslau wiederholt beobachtet, ohne dass ich in der Lage wäre, genaucre I)etails ïber die einzelnen Fïlle anzugeben, doppelseitig habe ich die Erkrankung nur sinmal gesehen und ich mache darauf aufunerksam, dass auch $\mathrm{K} \ddot{\mathrm{n}} \mathrm{nig}$ die Doppelseitigkeit des l'rocesses nicht als nothwendiges l'ostulat fordert. So lange ich ïber ein eigenes Krankenmaterial verfüge, habe ich zunächst eine 36 Jahre alte Frau operirt, welehe nicht geboren hatte und die Krankheit in ausgesprochener Weise, allerdings nur auf der einen Brust, darbot. Sie ist nach Amputation bisher ( 1 Jahre) gesund reblichen, die andere Manmma erkrankte nicht, ferner habe ich eine 42 Jahre alte Frau und ein 3!) Jahre altes lediges Fräulein operirt, die beide auf der recliten Brust den grleichen Befund darboten. Man konnte deutlich melirere kleine derbe Knoten in der Brust nachweisen, die in ein zienlich hartes (rewebe eingebettet erschienen. Dieselben erwiesen sich bei der Operation als haselnussgrosse Cysten, welehe in dem Zwischengewebe von einer ganzen Anzahl kleiner und kleinster Cysten begleitet waren. Elbenso war es bei einer 16 Jahre alten Dame, die ebenfalls nicht geboren latte, nur sass die Affection lier links und es fanden sich neben vielen kleinen, sehr typiseh in der Mammasubstanz angeordneten, namentlich an der IIinterfläche sicht- 
baren Cysten, noch 3 etwa wallnussorosse an der Vorderseite, die einen sriunlich-braunen Inlalt zeigten.

Diese Fälle sind von mir mikroskopisch untersucht worden; da sic klinisch nichts eraben, was von dem bekannten Krankheitshild ahweichend war, so veryichte ich darauf, eine detaillirte Krankengeschichte derselben zu liefern. Ich will nur bemerken, dass dic von anderen Dutoren betonte schubweise Fxacerbation des Processes nicht zu beobachten war. Finen Fall, der wenigstens scheinbar hierher gohört, muss ich aber, serade weil es sich nur um eine scheinhare /usammengehörigkeit handelt, genauer mithoilen. Fs handelt sich nämlich un einen Knaben, welcher auf beiden Bristen eine Erkrankung darbot, welelie nach den makroskopischen Befunde durchaus in das besprochene Krankheitsbild hincingehürte.

Fall I. Louis B., Schuler, 16 Jabre alt, stammt aus gesunder Familie und ist bis Januar 1999 immer gesund gewesen. Da bildete sich in der linken Mamma olne bckannte Ursache unter lebhaft zichenden Schmerzen eine Geschwulst heraus, die nach und nach ziemlich hart wurde. Nach ungefähr 3 monatlichem Bestande der Krankheit wurde der Zustand stationär, die Schmerzen liessen nach. Lm diese /eit entstand aber in der rechten Brust unter denselben Erscheinungen eine äbnliche Geschwulst, wclche cbenfalls nach relativ langsamem, melirmouatlichem Wachsthum ihren Höhepunkt erreichte. Von da ab blieben beide Geschwülste ohne nachweisbare Veränderungen, sie reagirten aber auch nicht auf die von verschiedenen Aerzten angewandten Mittel. Deshalb suchte Pat, die Aufnahme in die Klinik nach.

Status: Blasser, für sein Alter ziemlich grosser, schwächlich gebauter Knabe, dessen innere Organe sich als gesund erweisen. Beide Manmae bilden schon äusserlich sichtbare, prominente flache Köruer von der Grüsse etwa ciner halben Wallnuss. Die Mamillen bilden das Centrum für die Anschwellungen und zeigen in Form, Grösse und Lage keine Besonderheiten. Bei der Palpation erweisen sich die vorhin geschilderten Gebilde als flach scheibenförmige, relativ derbe körper von körnigem Gefüge, welche nach allen Seiten gut abgegrenzt sind und sich auf den Pectorales leicht verschieben. Druck auf dic Gescliwïlste ist nicht schmerzhaft, Drüsen in der Achselhöhle nicht zu fühlen. In der Annahme, dass es sich um Fibrome der Brustdrüsen handelte, werden beide Körper entfernt. Die Präparate entsprechen in äusserer Form und Beschaffenheit den soeben beim Cystadenom skizzirten Befunden. Luf dem 1)urchschnitt sieht man eine derbe, die ganze Manma einnehmende Gewebsmasse, in welcher aber, schon äusserlich sichtbar, eine Reihe friner, durchsclieinender Stippchen erscheinen, welcbe bereits äusserlich an die uns bekannten Mammacysten erinnern, nur dass sie von minimalster Grösse sind. Dic mikroskopische Untersuchung aber ergiebt, dass es sich um eine diffuse Erkrankung beider Mammae im Sinne eines Fibro. adenoms handelt, d. h. das intercanaliculäre Bindegewebe hat erheblich zugenommen, ist jung und kernrcich, aber olne Leukocyteninfiltrationen; 
Ausfuhhrungsgänge und Drüsenbläschen sind zu langen SchläucLen und Hohlräumen ausgezogen, die aber stellenweis deutliche Faltungen erkennen lassen, sodass ungeschickte, grobe Fortsätze in die Lumina vorzuspringen scheinen. An anderer Stelle bildet das Litbel feine warzenälnliche Vorsprünge in die Lumina hinein.

Dieser Fall schien uir, abgesehen von dem mehr zufälligen Interesse, lass es sich hier einmal ausnahmsweise um ein männliches Individuum handelt, deswegen erwähnenswerth, weil er zunächst zeigt, dass in der uns interessirenden Frage das Mikroskop entscheidet: klinisch und makroskopisch liätte man die $\Lambda$ ffection gewiss für ein Cystadenom halten müssen. Es ist aber - und das ist ein zweiter Grund zur Mittheilung - freilich nicht zu verkennen, dass dieser l'rocess bei dem Knaben in der $A$ rt, wie er diffus beide Nammat' befallen und zu einer gleichmässigen V'rmehrung ron Epithel und Bindegewebe geführt hat, thatsächlich vicles mit dem Cystadenom gemein hat. Vielleicht ist im späteren Verlauf der $\Delta$ rbeit noch cinmal Gelegenheit, auf diesen l'unkt zurückzukommen; vorlïufig sei dieser Punkt, um die Sache nicht noch nechr zu compliciren, verlassen.

Wenden wir uns vielmelir zu der Untersuchung der anderen drei Fälle. Zu diesen muss ich bemerken, dass in allen die $\Lambda$ ffection einseitige war, dass ich aber doch kein Bedenken trage, sie für typische Fïlle ron Cystadenom zu halten, ehen wegen des grleich zu schildernden mikroskopischen Befundes.

Betrachtet man nun einen mikroskopischen Schnitt aus den genannten Gebilden mit blossem Auge, so fällt zunächst eine grössere Menge bald grösserer bald kleinerer rundlicher Hohlräume auf, welche theils eng aneinander liegen, theils weiter von einander entfernt im Gewebe sich vorfinden.

Die mikroskopische Beschreibung setzt am besten bei den drusigen Bestandtheilen ein. Bei meinen ersten beiden Patientinnen fanden sich dieselben im Ganzen nur spärlich vor und umgeben von einem mächtigen, ziemlich kernarmen Bindegewebe, welches nicht selten in Form breiter concentrischer linge die Alveolen bezw. die Ausfulhrungsgänge umgab. Nur die unmittelbare Nachbarschaft der Alveolen ist etwas reicher an jungen Zellformationen; hier finden sich im Gewebe auch zahlreiche Leukocyten, ohne dass man berechtigt wäre, von einer entzündlichen Infiltration zu sprechen.

Anders war es im dritten Falle: die Zahl der driisigen Bestand. theile war hier auffallend gross, dass man an eine Neubildung derselben denken konnte. Jlier zeigte das interstitielle Gewebe auch stellenweis, namentlich in der Nachbarschaft der grossen, zum Theil ihres Epithels beraubteu Cysten, cine so starke Anhäufung von Leukocytenschwärmen, dass es als entztindlich infiltrirt angesprochen werden musste.

Betrachtet man nun die Alveolen etwas genauer, so finden sich doch schon an sehr vielen, die Anfangs normal erschienen, eine Reihe von 
Veränderungen. Sehr viele sind taber die Norm erweitert, zuweilen etwas unregelmässig gestaltet. l)

In einigen finden sich mit Eosin dunkelroth gefärbte und bomogene Massen (Secretionsproduct). Gelt man dann etwas weiter, so trifft man

Fig. 1.

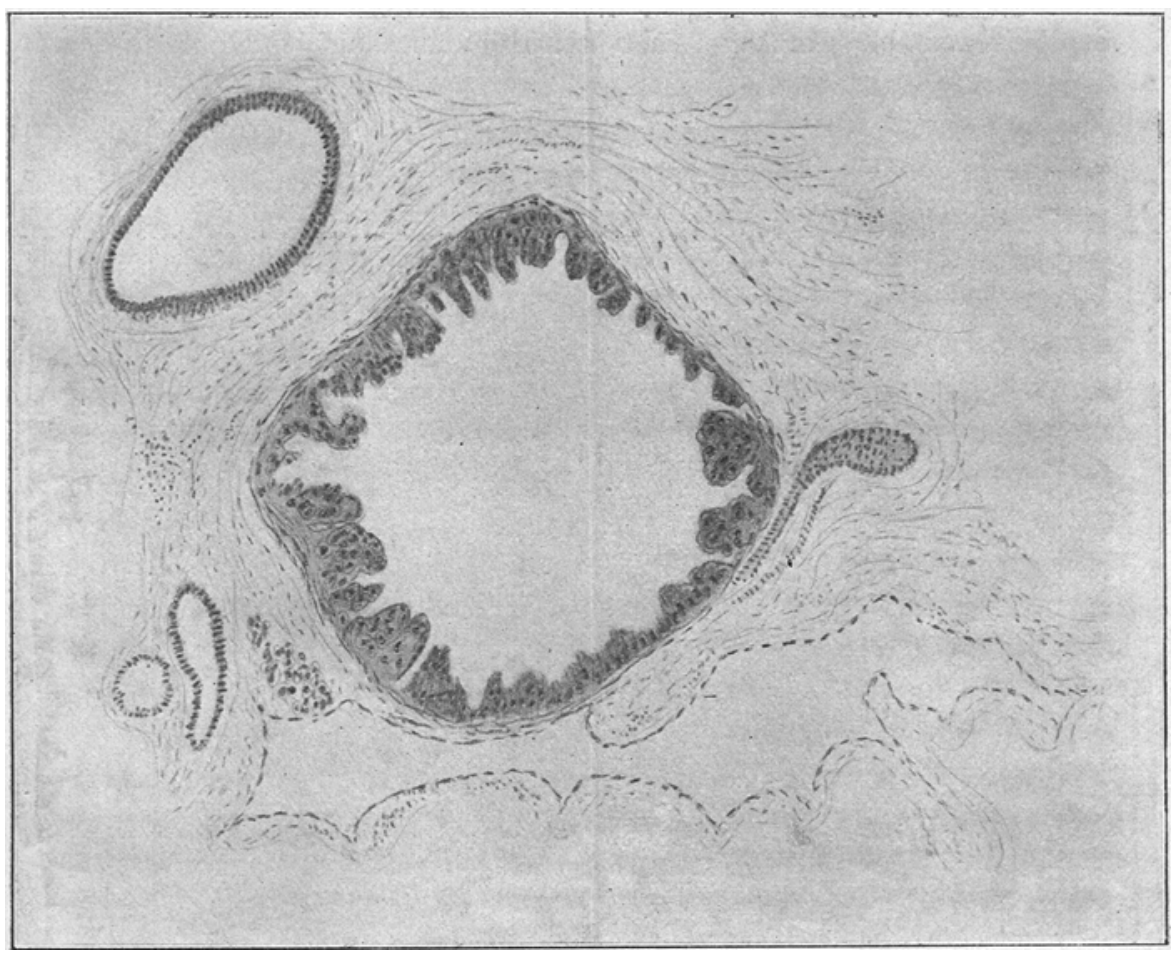

Alveolarepithel beginnt zu wuchem und kleine Zaplen zu formiren bei gleichzeitiger Erweiteruug des Binnenraumes.

Drüsenbeeren, in denen die Erweiterung bereits erhebliche Fortschritte gemacht hat. Hicr sieht man ein ganzes System (auf dem Querschnitt) von eng aneinander liegenden Ringen, die ganz unverkennbar weit uber

1) Jje Zalli dor vorbandenen Aeini ist beim Crstadenom rerschichen. Wïhrend sie in meinen Pläiptuaten nach dem Obigen wechselte, fanden sie andere Beobachtes durchweg vermelnt. Es glichen dadurch dio erkrankten J)rïsenabschnitte häufig piner lactirenden Namma, und es sit wiederholt die Frage aufgeworten worden, ob es sich $\mathrm{nm}$ eine Xeubildumg ron Driisenacinis oder um eine Frweiterumg und seitliche sprossmor sthon rorfandener hamdele. Der Sache nach dürtte wohl beides auf dasiselbe himauskommen.

Sasse hat auf die domelte Conturirung der erweiterten Driisenbeeren auf-

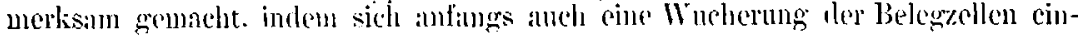
stellte. 
die Norm vergrösserten Drusenalveolen und Drüsenschläucheu entsprechen. Hier tritt nun ein neues Moment auf, nämlich die Epithelvermehrung, und zwar siebt man in das Lumen der durchschnittenen Hohlräume eine Reihe ganz kleiner Zackeu und Knöpfehen vorspringen, welche bei näherer Betrachtung sich als aufeinandergethürmte Epithelzellen erweisen. In diesen Epithelzapfen kann man von einem bindegewebigen Gertlst nichts erkennen, bald aber tritt auch dieses in die Erscheinung und zwar in folgender Weise: Sucht man sich die grösseren, schon Eingangs erwähnten, theilweise mit blossem Auge sichtbaren Hohlräume auf, so sieht man die-

Fig. :.

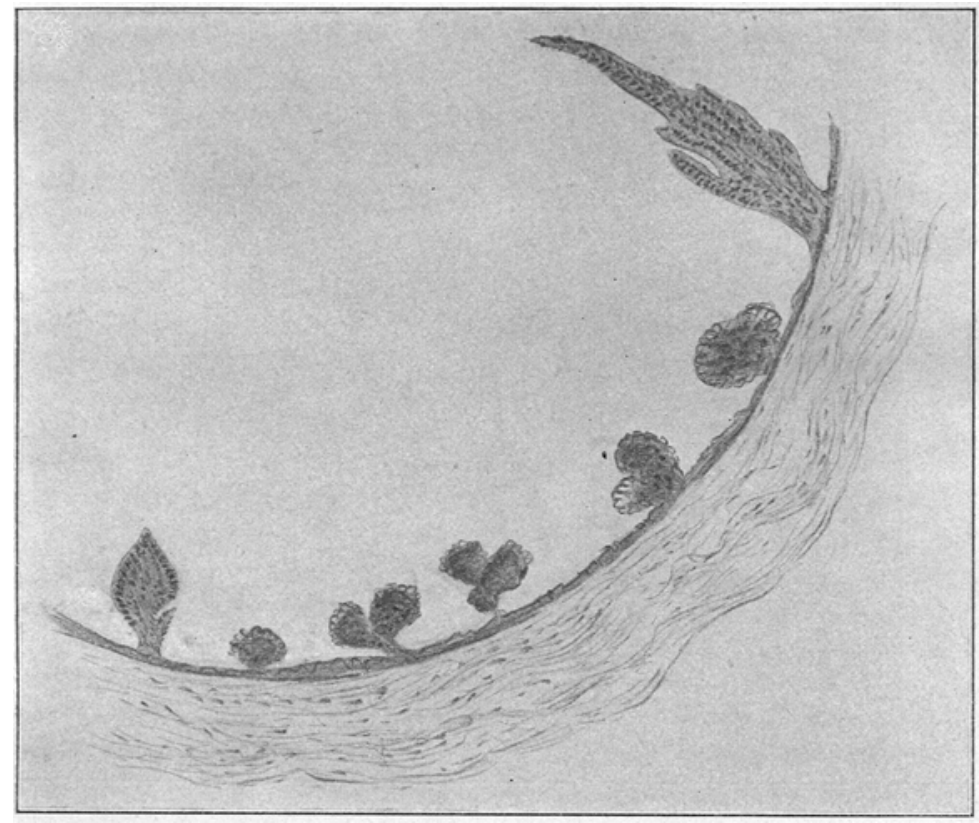

Zottenbildugy im Cystadenow, die Fpithelzapien weisen bereits stellenweise cin bindegewebiges Gerüst auf.

selben ausgekleidet von einer ein- oder mehrfachen Lage von niedrigem kubischen Epithel, das sich stellenweise ebenfalls zu ähnlichen Epithelspitzen formirt, wie eben geschildert, von dem sich aber an andercn Steilen dentliche Zotten abheben, die in Form von einfachen Spitzen oder aber von dendritisch verzweigten Kolben und papillären Wucherungen in das Lumen vorspringen und die alle das Gemeinsame haben, dass sie einen, häufig freilich nur aus einen Faden bestehenden bindegewebigen Grundstock haben, vermittelst dessen sie mit dem concentrischen die kleine Cyste umgebenden Bindegewebe zusammenbängen. An manchen Stellen ist allerdings dieser bindegewebige Antheil der Zotte nicht so 
dünn, im Gegentheil, er nimmt zuweilen den grössten Theil der Hebung ein und das ganze Gebilde schaut dann in Form eines plumpen Fortsatzes in das Innere. Nicht selten licgen dann in der ganzen Peripherie der Cyste Zotte an Zotte dicht nebeneinander, sodass es ganz aussieht, als bätte sich ein ursprünglich gleichmässig rund angelegter Hohlraum in verschiedene Falten gelegt. Noch an anderen Stellen finden sich

Fig. 3.

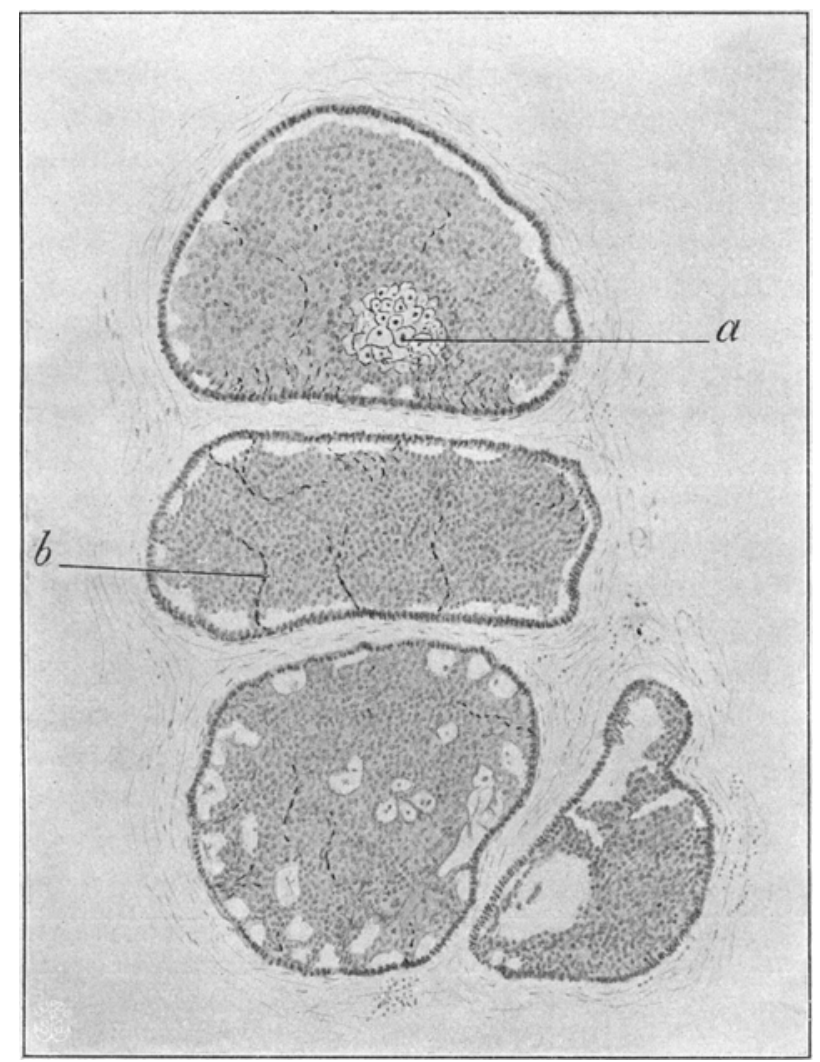

Wucherung der lipithelien bis zum völligen tusguss des Alveolus. Theilweise begreneration der Zcllen ( $(\prime)$. In den Zellhaufen sielht mau (b) feine Biudegew elsfäden.

Bilder, welche ganz den von Schimmelbusch beschriebenen Präparaten entsprechen. Es finden sich nämlich hicr ausserordentlich stark vergrösserte Drüsenalveolen, welche dicht vollgepfropft sind mit Epithelzellen, die sich so aufeinanderthïrmen, dass das ganze Lumen des Hohlraums ausgefullt erscheint. Bald aber machen sich an diesen Zcllcomplexen Degenerationserscheinungen geltend, die entweder dazu führen, dass das Innere der Zellenhäufung zerfällt, oder aber, dass sich versehiedene 
voneinander getrennte Zerfallscentren bilden, welche ebenfalls jedes fiir sich eine rundliche Gestalt besitzen und dem ganzen Gebilde ein eigenthitmlich wabenartiges Aussehen verleihen. Den Grund dieser eigenthiumlichen Zeichnung konnte ich darin finden, dass sich auch in das Lumen des ganz mit Zellen vollgestopften Alveolus feine Bindegewebsmaschen von der Wand aus Lineinschlingen, welche einzelne Felder dieser Zell-

Fig. 4.

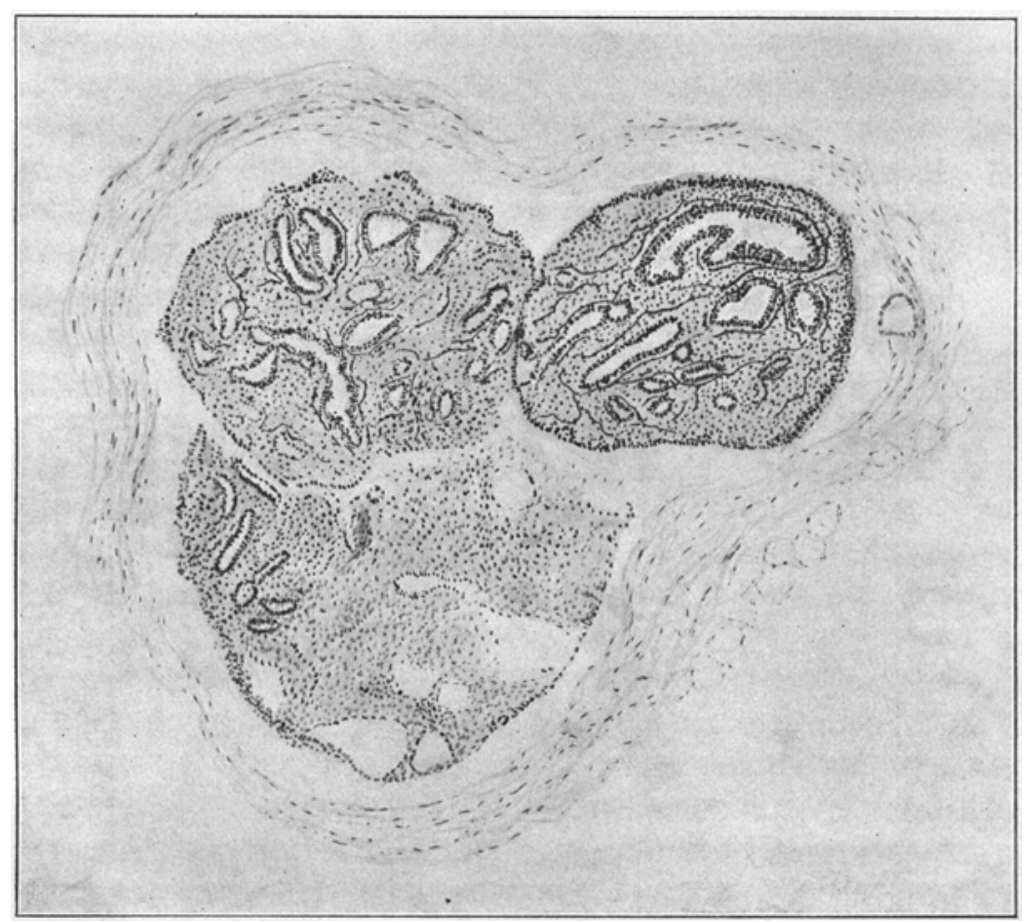

Cystadenom, dasselbe Prijparat wie: in Fig. 1. Intracanaliculïre \%otte mit Drüsenbildung.

maschen voneinander trennen. Durch Zerfall einzelner Zellgruppen, vielleicht auch manchmal in Folge mechanischen Ausfalls bei der Präparation, entsteht jene eigenthilmliche, auch von $\mathrm{Sasse}$ und Roloff beobachtete Zeichnung.

Die Zelldegeneration war namentlich in meinem $z$ weiten Falle recht deutlich zu verfolgen, bei welchem man beobachten konnte, wie zuerst las Zellprotoplasma sich in eine körnige Detritusmasse auflöste, wälırend der Kern noch relativ lange färbbar blicb, bis auch er dann schliesslich sich auflöste.

Bei diesem Falle fand sich aber noch etwas Eigenthilmliches, indem sich in manchen Cysten ganz deutliche Andeutungen jener adenomartigen 
intracystischen Gebilde fanden (Fig. 4), welche wir bei den intracanaliculären Cystadenomen der Mamma so bänfig treffen werden. - Die Epitbelveränderungen fanden sich namentlich an den Alveolen ausgesprochen, papilläre Erhebungen und Rankenwerk waren nur in diesen zu finden, dagegen war auch das Epithel der Ausfuhrungsgänge gewuchert, dieselben erschienen zum Theil mit Zelldetritus erfüllt.

Das Verhalten des Bindegewebes erhellt aus dem zu' Anfang der mikroskopischen Besclıreibung Gesagten.

Was ich an diesen Befunden ganz besonders hervorheben möchte, ist der Unstand, dass sich unter den 3 Mammae keine fand, welche genau dem von Schimmelbusch geschilderten Typus in allen ihren Teilen entsprochen hätte.

Die Ausfïllung der Aveolen mit rewucherten Fithelien war überall rorhanden, aber daneben fanden sich, wie gesagt, reçelnä̈ssig Cysten von anderer Form und mit papillären Excrescenzen. Wie weit wir berechtigt sind, auch diese in das Bild des von Schimmelbusch gezeichneten Cystadenoma mammae hineinzubeziehen, werden wir an anderer Stelle besprechen. Vorerst will ich nur hervorheben, dass, wie schon bemerkt, auch Sasse und Roloff über älnnliche Befunde berichtet liahen, ohne in denselben etwas von den Schimmelbusch. sclien Befunden prineipiell $\Lambda$ bweichendes zu erblicken.

Sehr rein fand ich dagegen die Sclimmelbusch'schen Bilder wieder in einer Reihe ron Mammacarcinomen, welche ich in den letzten Jahren operirt habe. Es sind deren im Ganzen 5. Es handelt sich dabei um Patientinnen, welehe alle im vierten bezw. im Begrinn des fünften Decenniums standen; sic boten in Bezug auf Anamnese und Befund nichts dar, was sic vor anderen Carcinomen der Brustdrüse ausgrezeichnet hätte. Frwähnt magn nur werden, dass bei einer der Franen aus derselben Brust 6 Jahre vorher ein eystischer 'Tumor entfernt worden war. Am markantesten fanden sich die fracrlichen Veränderungen aber nicht bei dieser, sondern bei einer anderen latientin, wclche daher auch als Prototy' für die anderen grelten kann.

Fall It. Frau F., 44 Jabre alt, noch menstruirt, hat 2 kinder gehabt, dieselben aber nicht selbst gestillt; schlimme Brust hatte sie nicmals; mit Ausnahme eines Lnterleibsleidens vor einem Jabr ist sie immer gesund geblieben, ihre jetzige Erkrankung wurde bemerkt vor ca. 8 Wochen, wo sie zufällig eine kleine Verhärtung in der recliten Brustdrüse merkte. Sic lsat dieselbe zunächst verheimlicht, dann aber, als es ihr schien, als $o b$ dieselbe wüchse, ilrem Arzt gezeigt. Bei der jetzigen Untersuchung findet sich eine mittelgrosse, etwas blasse, gracil gebaute Frau, deren innere Organe Pathologisches nicht darbieten. Temperatur normal. Puls so, kräftig. Im äusseren oberen Quadranten der rechten Mamma findet sich, schon äusserlich sichtbar, ein ca. hühnereigrosser Tumor, welcher sich auch noch in die untere Hälfte der Brustdrïse hinein erstreckt. Die 
Haut itber demselben ist nicht verändert, die Mamilla nicht cingezogen. Bei der Palpation erweist sich dieses Gebilde als ein derber, in die Substanz der Mamma eingebetteter Knoten, welcher eine etwas höckerige Oberflïche besitzt, auf Druck Sclımerz nicht bereitet. Druck auf die Geschwulst lässt aus der Mamilla keine Flüssigkeit hervortreten. Der Tumor ist mit dem Pectoralis nicht verwachsen, in der Achselhöhle sind eine Anzahl geschwollener Drüsen zu fühlen, die Schlïsselbeingruben sind frei. In typischer Weise wird der Patientin die Mamma im 'Lusammenhang mit dem gesammten Inhalt der Achselböble exstirpirt und ebenso der Pectoralis major abgetragen. Der gesetzte Hautdefect lässt sich durch Naht nicht vollständig schliessen, die Achsselhöhle wird durch Anlegung einer Oeffrung an ibrem tiefsten Punkte, aber ohne Zuführung eines Drains oder Gazestreifens drainirt. Die Patientin verlässt nach nicht ganz 3 Wochen mit granulirenden Wunden das Hospital und ist bis jetzt, d. b. 3 I Jabr nach der Operation recidivfrei.

Der durchschnittene Tumor stellt einen hühnereigrossen, ziemlich gut isolirten Knoten dar, welcher etwas körniges Gefilge besitzt und von weissröthlicher Farbe ist. Genauere Structurverbältnisse lassen sich mit blossem Auge nicht erkennen.

Sieht man sich nun das mikroskopische Präparat an, von Stellen der Randpartie, so sind es zunäclsst zwei Dinge, welche auffallen, 1. hat das Bindegewebe der Mamma erheblich zurenommen und umgiebt theils in Form dicker concentrischer Ringe Alveolen und Schläuche, theils zieht es sich in Form breiter Bänder zwischen denselben hindurch und 2. sieht man all die Veränderungen an den Alveolen, welche Schimmelbusch als charakteristisch für sein Cystadenoma mammae beschrieben hat, d. h. während ein Theil der drtsigen Bestandtheile durch die Bindegewebsentwicklung zusammengedrückt, verengert und verkleinert erscheint, spielt sich an dem bei weitem grösseren Theil derselben ein Process $a b$, der darin besteht, dass das Epithel der Alvcolen und scheinbar auch der Drüsenschläuche sich enorm vermelırt, so sehr, dass die ganzen Alveolen und Scbläuche absolut mit Zellen vollgestopft sind, wobei diese Alvcolen eine enorme Vergrösserung erfahren. Trifft man noch die Anfangsstadien des Processes, so kann man an der Gruppirung dieser zellerfüllten Gebilde noch deutlich die Structur des Acinus, d. h. die Zeicl. nung der Drttsenbeere erkennen, später aber, wenn bei zunehmender Grösse die Alveolen auseinanderriicken, so ist das durchaus nicht mehr so leicht möglich, auch trägt hier noch ein zweiter Umstand dazu bei, die ursprüngliche Form unkenntlich zu machen, indem nämlich ein Zerfall des Zellhaufens eintritt. Wir haben denselben schon fruher beschrieben und wollen nur noch cinmal constatiren, dass auch hier sowoll der primäre zur Cystenbildung fülırende Zerfall in der Mitte zu beobachten ist, als auch das Auftreten von verschiedenen 'Zerfallsherden, wodurch sie wieder die uns bereits bekannte wabenartige Zeichnung erhalten. Dass man es nicht als Uebergang zum Careinom bezeichnen darf, wenn an vielen Stellen zwischen benachbarten Alveolen die Seitenwand verschwindet, sodass dieselben mit einander confluiren und ein eiuheitliches, durch eine eigenthilmliche Semmelform ausgezeichnetes Bild liefern, ist klar, dagegen finden sich unverkemubare Uebergänge zum Carcinom an anderen 
Stellen. Schon bei einzelnen kleinen Alveoleu, haufiger noch bei grösseren, gefullteren sieht man, dass die ursprïngliche runde Form nicht beibehalten worden ist, sondern offenbar ist die Wand durchbrochen und die Zellwucherung streckt unregelmässige Fortsätze in das benachbarte

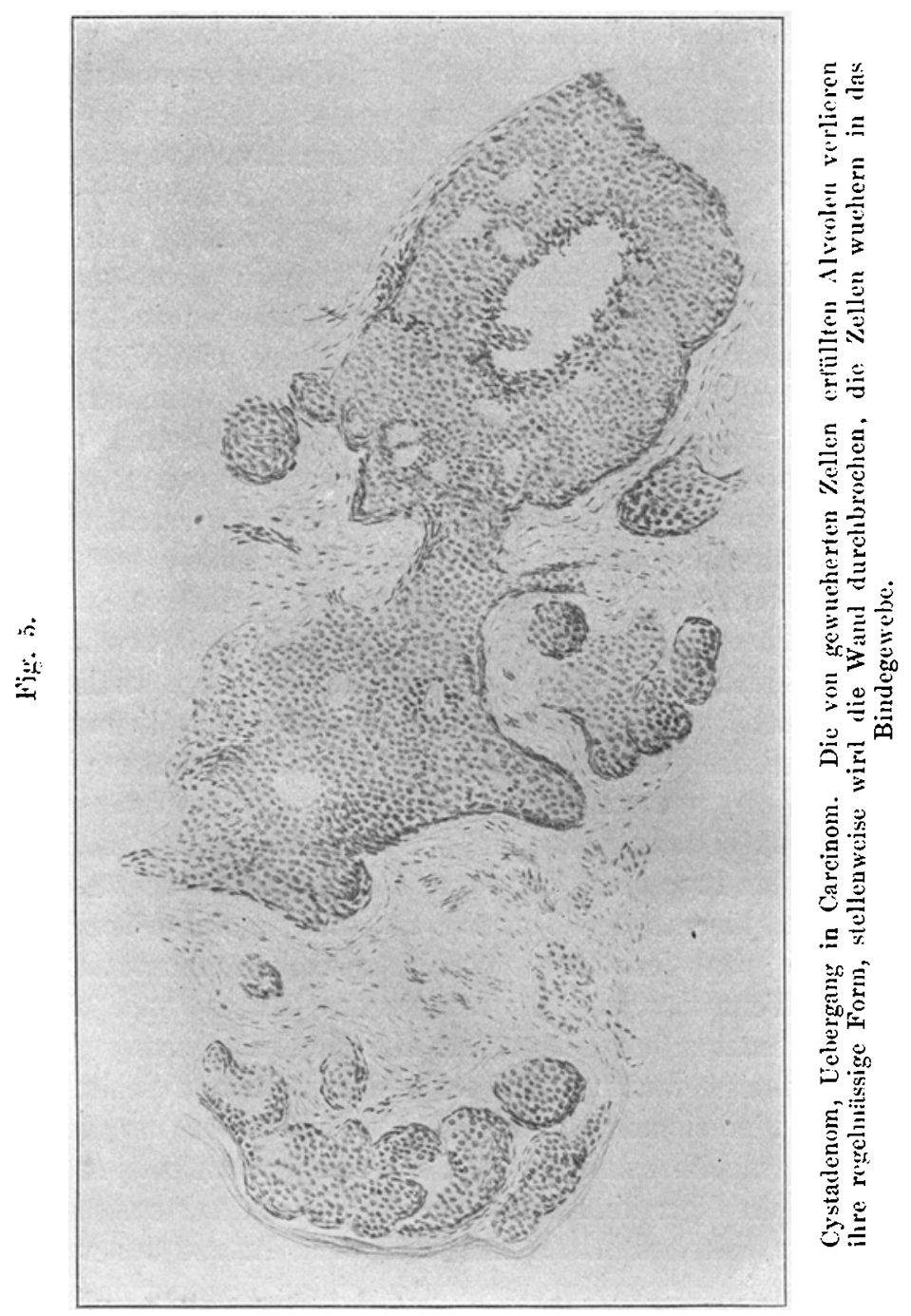

Gewebe hinein. Schon in diesen Randpartien sieht man dann in denselben eben geschilderten Präparaten an anderen Stellen nichts mehr von den urspriinglichen Alveolen, sondern wir finden einfach das Bild eines zellreichen, das Gewebe durchwuchernden Carcinoms. Diese 
letzteren Bilder sind in der Mitte der Geschwulst vorherrschend, es findet sich einfach das Bild eines Carcinoma simplex manmae. Dasselbe war auch in dell Drüsenmetastasen vorhanden.

Schliesse ich hiermit zunächst nun die Reihe mikroskopischer Beschreibungen ab, so fragt es sich nun, ob es sich in meinen Fïllen wirklich um die Schimmelbusch'sche Frkrankung wehandelt hat, es fragt sich 2., was wir uns von dem Wesen dieses Processes für eine Vorstellung machen sollen und es ist 3. die Frage zu beantworten, ob die beim Carcinom geschilderten Processe als secundäre, durch das Wachsthum des Carcinonıs hervorgerufene Reizsymptome zu betrachten sind, oder aber ob wir in der Wucherung der Nveolarepithelien das Primäre und in dem Carcinom den Ausdruck des secundiiren Findringens der gewucherten Epithelien in das Bindegewebe erkennen sollen. Was die crstere Frage anbetrifft, so glaube ich diese ohne Weiteres bejahen zu dürfen, denn wenn unsere Bilder auch etwas von der Beschreibung von Schimmelbusch abweichen, so thut dies den Wesen der Sache doch zweifellos nichts. Stand bei Schimmelbusch die Beschreibung, jener mit gewueherten Epithelien erfüllten Drüsenalveolen im Vordergrunde des Bildes, so können wir die von uns so häufig beobachteten Cysten mit einfachem Epithelbesatz aber zahlreichen papillären Erhebungen diesen Epithelvermehrungen als principiell identisch an die Seite stellen. Derartige Bilder kennen wir von verschiedenen entzïndlichen Processen, wir kennen sie aus anderen cystischen Tumoren (Ovarialtumoren, Pfannenstiel Lehrbuch von Veit) und wir kennen diesen eigenartigen Process der Anordnung neugehildeter Epithelien auch aus den melir dem Normalen sich nähernden Processen. Lm letzteres festzustellen, liegt es für mich an nächsten, hier an den Vorgang zu erinnern, anf wolchen ich bei einer Reihe von Versuchen ïber Netzplastik aufmerksam machen konnte'). Wenn nämlich Netz 7. B. in eine Magenwunde einheilt, so ist es interessant zu beobachten, wie sich die Epithelisirung de's sehnell seines Endothels beraubten und entzündlich infiltrirten Netzes vollzieht. Man sieht hierbei urspriinglich von den Rändern der Netzplombe aus das Magenepithel zunächst in Form einer cinschichtigen Cylinderz.elllage auf das Netz hiniiberkriechen. Schr bald bekomnit aber diese Zelllage eine Falte, es erhebt sich nach dem Innern des Magens zu ein Ejithelkexel, dessen Inneres durch einige Leukocyten ausgefüllt ist. Sehr bald aber wird aus dieser Epithelerhebung eine rielitige kleine 7otte, welche einen bindegewebigen Grundstock besitzt; und sieht man das Endstadium des Processes an, so weit ich es wenig.

1) Bruns' Beitrïine. Bul. $\times x v$. 
stens verfolgt luabe, so findet man das enorm geschrumpfte Yetzstiick bedeckt mit einer drt neuer Magenschleimhant, welcher allerdings die Muskellage der Submueosa fehlt, die aber der normalen Marenschleimhant insofem gleicht, als sie 1. eine keihe ron allerdings unregelmässig gestalteten Zotten besitzt und als sie 2. in der Epithelbekleiduny der Zotten sowohl, als im Grunde der durch das Zusammenstossen zweier benachbarter Zotten gebildeten Vertiefungen zahlreichen Drïsen bildct. leh habe auch am angegebenen Orte ein Prïjarat abgebildet, welches noch ein selır frühes Stadium darstellte, wo gerade erst auf dem noch nicht vollstïndig epithelisirten Netz eine cinfache Zellage mit einer einfachen Epithelfaltung erschienen war, wo sich aber bereits unter dieser Zelllage der Durchschnitt cines neu gebildeten I)rïsenlumens zeigte.

Die Entstehung eines Tumors ist nun aber nicht eine so abnorme Erseheimung, dass wir nicht in suinem Wachsthum Inklänge an das physiologische Werden erblicken müssten, und so nuss ich denn sagen, dass jelı in der Art und Weise, wic sich die kleinen Epitleelzacken in den wuchernden Alveolen bilden, wie ferner in denselben allmählich bindegewebige Elemente entstehen, genau denselben Vorgang erblicken muss, wie in der Beklejdung und Zottenbildung auf dem Netzstumpl, d. h. mit andern Worten: Die Epithelzacken und bindegewebienen Zotten in den kleinen Mammacysten sind nur ein Ansrlruck für die begimnende Epithelvermehrung, sie stehen daher principiell mit der völligen Ausfïllung der Alveolen mit Epithelzellen auf einer Stufe und wir haben daher ein Recht, unsere Fälle als typische Fälle von C'ystadenom anzuschen. Wenn nun dic Analogie mit der Netzepithelisirung vollständig sein sollte, so müssten wir auch erwarten, dass die Bekleidung der Zotte auch in den Mammacysten im Stande wäre, sich zu Drüsenformationen umzubilden und in der That ist dies auch in schönster Weise zu beohachten, denn dicse Ansicht gieht uns die Erklïrung für Figur 5, wo wir solehe Einstïlpungen auf einer Zotte leobachten.

Bestelit num in der Epithelvermehrung die hervorstechendste Eigenthïmlichkeit des Cystadenoms, so ist 2. nun die grosse Frage, ob man hercehtigt ist, diesulbe als eine entziundliche aufzufassen. Kö̈nig führt zum Beweis dafür an, lass er im interstitiellen Gewebe zahlreiche entzündliche IIerde beobachtet habe. Auch Roloff hat solche entzündliche Ilerde beobachtet und sielt vor allen Dingen in der Verdickun und Sklerosirung des Bindegewebes den Lusdruck eines entriundlichen Processes. Er weist ferner darauf hin, dass wir ja ähnliche Epithelvermehrungen ron entzündlichen Processen an 
Magen und Darm kennen, so dass es als nichts Auffällizes erschiene, auch bei der Mamma in der Epithelvermehrung das Resultat der Entzündung zu erblicken. Dacergen ist nach meiner Ansicht wohl doch Folgendes zu sagen: es ist nicht zu leugnen, dass Epithelrermehrung auf einen cntzïndlichen Reiz hin stattfinden kann, alser der gewöhnliche Ausilruck einer lintzündung ist dies nicht, im Gezenteil antworten die drüsigen Organe auf eine Entzündung in der Regrel mit einem Lntergang ilures Epithels, und bei den in ihrem histologischen Bau der Mamma doch immerhin verwandten Speicheldrüsen kann man z. B. diese Veränderungen, welche zu einem vollständigen Schwund der driisigen Bestandtheile fülıren, in selır interessanter Weise beobachten. Was ferner die interstiticllen Processe in Bind'gewebe, namentlich die kleinzelligen Infiltration anbetrifft, so ist sehr sehwer zu entscheiden, was Ursache und was Folge oder Begleiterscheinung der sich in den Acinis alspiclenden Erkrankung sein würde. Wir wissen ja, welch mächtiges Gefolge von liundzelleninfiltration einen wachsenden Tumor becrleitet und wir mïssen die Vermelirung und Neubildung von Zellen in Alvonlus in diesem Simne als Entzündungsreiz gregenüber der Nachbarschaft betrachten: und was die V'rdickung des Bindegewebes anbetrifft, so handelt es sich meistentheils um ältere Patientinnen, in denen dies Bindegewebe so wie so an Menge zugenommen hat. Somit glaube ich, dass wir aus dem objectiven mikroskopischen Befunde allein die Frage nach der Bedeutung des Processes nicht werden entscheiden kïnnen, sundern dass wir es aus anderen Gesichtspunkten heraus thun müssen. In diesem Sinne glaube ich, dass wir die nahen Beziehungen des Cystadenoms zum Carcinom der Brustdriise verwerthen können.

Beschäftigen wir uns daher zunächst mit der dritten vorlin aufgew orfenen Frage, ol die dem Cystadenom so ähnlichen Bilder beim Carcinom Symptome cines besonderen Epithelreizes durch das wachsende Carcinom seien.

Diese Ansicht ist sicher nicht ohne Weiteres $z u$ widerlesen, ja sie besteht wohl für einen Theil der Veränderungen zweifellos zu Recht, nur ist es fraglich, ob sie auch für alle Fälle gültigr ist. Wenn ein Carcinom in der Brustdrïse beginnt, so fangen die Epithelien der Drüsenalveolen an zu wuchern und es erschcint ganz selbstrerständlich, dass sic nicht von $\Lambda$ nfang an dic Wand der letzteren durchbrechen, sondern sich da ausbreiten werden, wo sie Platz, wo sie den geringsten Widerstand finden, und so wird es ein Stadium geben, wo das Brustdrüsenearcinom dem sogenannten Cystadenom sehr ähnlich aussehen wird. Dass wir dieses Stadium nicht kennen, liegt einfach 
in unserer Lnfähigkeit, zeitig genug die richtige Diagnose zu stellen und früh genug zu operiren. Es ist also jedenfalls der Gedanke discutabel, ob nicht in einem Theil der Mammacarcinome die mit gewucherten Fpithelien erfüllten Drüsenräume nicht die Folge einer Reizung dureh das benachbarte Carcinom, sondern sellsst den Beginn einer carcinomatösen Wucherung und somit selbständige Carcinomberde darstellen. Dieser Annahme stände allerdings die Anschauung entgegen, dass cin maligner Tumor circumscript, von einem einzigen Herde aus beginnt und sich von da nach allen Seiten hin ausbreitet. Diese Annahne ist keine durchaus zwingende. Hat man mit derselben sehon bei der Erklärung des Wachsthums der sogenannten Endotheliome vielfach gebrochen, so ist sie auch für das Carcinom nicht absolut bewiesen. Maw lotzteres nun entstehen, wie es wolle, durch den Reiz eines Lebewesens oder durch denjenigen einer unbelebten Materie, durch ein Trauma oder durch eine Disposition, inmer wird es sich nicht nur un eine Zelle, um cinen Drüsenalveolus handeln, der ins Wachsen geräth, sondern derselhe Reiz, der so zalılreiche Zellen trifft, wird in vielen von ihnen, die als Theile desselhen $0 \mathrm{r}$ ganismus so nahe mit einander verwandt sind, dieselbe Eirscheinung, d. I. gesteigertes Wachsthum hervorrufen und erst im siäteren Verlauf, vielleicht durch einen Zufall wird sich dann die eine Zellgruppe stärker differenziren als die andere und ihr so vorauseilen, dass sie scheinbar den Begrinn des Tumors darstellt.

$\mathrm{IV}^{\mathrm{r}}$ enn wir ferner in den geschilderten Epithelwucherungen in den Aveolen beim Carcinom nur Reizerscheinungen erblicken, so müssten wir eigentlich erwarten, dass gerade diese Aveolen sieh an der Carcinomwucherung nicht betheiligen und doch glaube ich alle Uebergäinge ron diesen grefiiltten Alveolen bis zur wirklichen Carcinomentwickelung beobachtet zu haben, wofür Fìg. 5 ein, noch nicht einmal schr typisches Beispicl gieht.

lch muss daher sagren, dass ich die grefüllten Alveolarcomplexe beim Ilammacarcinom nicht cinfach als entzïndliche Erscheinungen oder als . Reizerseheinungen" betrachten kann, und was die Frage des Cystadenoms anbetrifft, so ergiebt sich aus dieser $\Lambda$ uffassung auf Grund der histologisch vielfach so ähnlichen Bilder, verbunden mit der Thatsache, dass das Cystadenom factisch etwa in 10 Proc. der Fälle in Carcinom überführt, dic Ueberzeugung, dass wir es bei dem Cystadenom nicht mit einem entzundlichen Process jm gewölntichen Sinne des Wortes zu thun haben. Es ist 
eine eigenartige Erkrankung des Epithels, aber als solche mit dem Careinom sehr nahe verwandt.

Sieht man in den sogenannten Cystadenomen einen entziindliehen Process, eine Mastitis, so ist damit grleichzeitig für die Frage der Entstehung" des Carcinoms ausserordentlich viel prijjudicirt, denn voum Cystadenom zum Carcinom ist nur ein selır kleiner Schritt: das eine ist wie das andere eine primäre Epithelerkrankung; aber gerade deshalb miissen derartige Erkrankungen un so genauer durchforscht werden, weil sie uns vielleicht für die Entstehung der Carcinone gewisse Aufschliusse versprechen.

Noch ist auf einen Einwand einzugehen, nämlich auf die Thatsache, dass sich im klinischen Bilde nicht selten schubweise Entzïndungserscheinungen an der kranken Brustdrüse geltend machen sollen. Allgemein wird dabei behauptet, dass dieselben namentlich zur Zeit

1) Ich hatte Gelegenheit, cin Nammacarcinom in einen schr frühen Stadium zu operiren. Ile Trägerin war eine 45 jïhrige Isame, dic seit Jahren in ter linken Brust einen kleinen Knoten batte, Iler ihr seit einigen Wochen ein eigenthiumliches Gefïhl der Spanmung vermeachte. Drüsen waren nicht vorhanden, der 'Tumor machte den Eindruck eines Fibroadenonıs. Beim Jurchschneiden des sueben exstirpirten Tumors weist derselhe cinen lappigen Bau auf, doch schien mir ein Lippehen, das auf dem Inurchschnitt noch nicht linsengross war, auf Carcinon verrlichtig. Ich amputirte die ganze لlamma. Xach cinem Jahr fiund sich local kein Recidiv, dagegen hatten sich im Jaufe der Ietzen Monate in der Supraclaviculargrube und am Halse kleine, larte, schmerzlose Irüsen entwickelt. Seit jener Zeit habe ich von der Patteentin nichts mehr gehört. Bei der mikroskopischen Lntersuchung erwies sich der grössere Theil des Tumors als ein sehr drüsenarmes, zum Theil verfettetes fïbroardenom; in jenem kleinen Läppechen war alber gewissermaassen ein reges l.eben vor sich gegangen; es fanden sich zahlreiche nengebildete Drüsensprossen, welche stellenweise direct büschelförmm angeordnet waren. Sehr deutlieh war in ihnen eine Vermehrung des Epithels ansgesprochen, das mitunter die drüsige Strurtur durch seine Massenhaftigkeit verwischte und an anderen Stelien bercits atypisch in das Bindegewebe eingeirochen war.

2) Fïr dic Auffassung des Cystalenoms Schinumelbusch als rein entzündlichon I'roecseses macht auch die häuffig beobachtete Doppelseitighkit des P'ro(esses gewisse Schwierigkeiten, jedenfalls müsste man dann schon annehmen, dass las infectiöse Material den Driisen im Blnte gugefïhnt wirt, dal es doch schr merkwürdig wäre, wemn mit solcher Häufigkcit ein von alussen kommenter Infectionsstoff den Wey in beide Irüsen fünde. Dam diurfte es sich wohl aber sicher zum mindesten um keine corpusculären Entzïndungserreger handedn, sonlorm um einen physikalischen orter vielmehr chemischen lieiz. Ob man mun einen solchen Process, der allmählich zorr Entartung eines Orgrans fïhth, als cine Lintzïndung bezeichnen soll, int fraglich, wem sich auch bei ihm gewise Zejchen der Fntzändung histologiseh zeigen. So vollzicht sich z. B. lhe Involution der Thymus anch histologisch unter einem 'ahhnlichen Bilde, nud doch sieht man in diesem histologischen Vorgang gewöhnlich keine Entzündung. 
der Menstruation bemerkt worden sind. Die Anamnese meiner Patienten bot hierfür nichts Charakteristisches; wenn aber diese Ingabe richtig ist, so ist sie doch ebenso für unsere Auffassung zu verwerthen als für die gregentheilige. Wir können uns vorstellen, dass auf Grund (ler lebhafteren Durchströmung der Drüse mit Blut zur Zeit der Menses eine Wucherung der irgendwie dazu disponirten Fpithelien eintritt. Naturgenäss wird sich diese mit einer Steigerung des intraalveolären Druckes und mit Secretstauung verbinden. Dass dann Schmerzen und andere entzündliche Erscheinungen in der Brustdrüse auftreten, braucht uns nicht mehr zu wundern.

Gruppe B. Das intracanaliculäre Cystadenom.

Dic zweite Reihe meiner Tumoren schliesst sich an jene Form der Lrkrankungen an, welche Sasse als intracanaliculäres Cystadenom bezeichnet. Ich will geewen diesen Namen, welcher den Process sehr treffend bezeichnet, durchaus nicht Protest erheben, möchte aber mir daran Zweifel zu äussern erlauben, ob die strenge Scheidung, welche fast alle Autoren zwischen Cystalenom Schimmelbusch und dieser Erkrankung machen, gerechtfertigt ist. Zunächst folgen meine eigenen Beobachtungen.

Fall I (hierzu Tafel II). Frau G. I., 60 Jahre alt, war bisher mit Ausnahme von lheumatismus immer gesund; Kinder hat sie nicht gehabt. Vor 8 Tagen bemerkte sie, dass ihr Hemd gegenüber der linken Brustwarze mit blutiger Flussigkeit getränkt war. Auf Druck entleerte sich aus der Warze dieselbe Flüssigkeit in Form grosser Tropfen. Schmerzen oder sonstige Beschwerden hat Patientin nic gehabt. Die Untersuchung ergiebt eine kleine Frau in mittlerem Einährungszustande, an der nichts krankhaft erscheint, als dass sie aus der linken Mamilla, an der sich einige Blutreste befinden, auf Druck ein blutiges Secret, dunnflüssig, aber klebrig in Form grosser Tropfen entleert. So lässt sich jedesmal vielleicht $1 / 2$ ccm ausdrucken. Sclimerzen hat Patientin dabei nicht. In der Tiefe der gut entwickelten Mammasubstanz etwa $1 \mathrm{~cm}$ unter der Haut liegend, fühlt man ganz deutlich eine leichte Verdickung in dem Mammagewebe, die nicht sebmerzhaft ist. Drtsen in der Achselhöhle sind nicht zu fühlen. Aus den noch zu erörternden Gründen wird die Amputation der Brust mit Ausräumung der Acbselhöhle gremacht, in der sich geselwollene Drüsen nicht finden. Die Inspection der amputirten Mamma ergiebt im Ganzen absolut gesundes Gewebe, aber dicht unter der Mamilla einen knapp bohnengrossen Tumor, der sich durch sein solideres Gefüge von der Nachbarschaft unterscheidet. Er erscheint auf dem Durchschnitt in Form einer röthlich-weissen Masse, die von einem kleinen, blutig verfürbten Spaltraum durchzogen ist. Auch in den solideren Theilen des Tumors finden sich noch eine Reihe blutiger Stippchen, weitere Structurdetails sind weder mit blossem Auge noch bei Lupenvergrösserung zu erkennen. 
Sehr interessant erscheint das Resultat der hist ologis chen Lnter suchung. Betrachtet man die gefärbten Schnitte, welche durch die ganze Länge des Tumors geführt werden konnten, mit blossen Auge oder bei Lupenvergrösserung, so entdeckt man in einem blassgefärbten Grundgewebe eine grosse Reihe von unregelmåssig gestalteten Hohlräumen, dic von einem etwas dunkler gefärbten, sclımalen, streifigen Saum um. grenzt sind. Zwischen den Hohlräumen liegen dunkler tingirte Gebilde, welche sich durch ibre charakteristische Form sehon als Drüsenbeeren verrathell. In den Hohlräumen aber finden sich solide, rundliche, intensiv gefärbte Gewebspartien, welche von dem Grenzsaum meist durch einen schmalen freien Spalt getrent sind, oder aber mit ihm in Form eines dünnen Stiels zusammenhängen und die bei nälerem Zuschen ebenfalls eine ganze Anzahl feiner runder Lucken enthalten. Diese Befunde werden durch die mikroskopische Untersuchung in folgender Weise ergänzt: Der Tumor lässt die Structur eines fast in jeder Beziehung veränderten Mammagewebes erkennen. Erstens hat offenbar eine starke Vermehrung der Dritsenbeeren stattgefunden, aber diese erscheinen fast nirgends normal, sondern sie treten auf in Form unregelmässig ausgezogener cystisch erweiterter Schläuche, an welche ebenso veränderte, aus Alveolen entstandene Endstitcke angesetzt sind. In die Wand dieser schlauchartigen Hohlräume springen sehr vielfach kolbige, aus Bindegewebe mit einer ditnnen Epithellage bestehende Hervorragungen ein, die gewöhnlich so breitbasig angelegt sind und aus so kernarmem Bindegewebe bestehen, dass es den Anschein erweckt, als seien dieselben durch Verzichung und Faltung des epithelbekleideten Hohlraumes entstanden und nicht etwa secundïr in denselben hineingewachsen. Ausge. kleidet sind diese Hohlräume von einem ziemlich niedrigen Cylinderepithel, das stellenweis ganz fehlt, meist aber einschichtig auftritt und mehrschichtig wohl nur da erscheint, wo die Gänge durch einen schiefen Schnitt getroffen sind. Je mehr nach dem Centrum zu, desto mächtiger werden die Erweiterungen der Drüsengänge und desto grösser und kugeliger ihre Endtheile. In der Mitte des Präparats findet man eine Reihe einfacher runder Hohlräume, ohne dass man eine Fortsetzung derselben in Drilsengänge beobachten könnte. Ausgekleidet sind auch diese yrossen Cysten mit dem einschichtigen Epithel, aber was ihnen ein besonderes Gepräge verleiht, ist der Umstand, dass sich in ihnen auf dem Durch. schnitt scheinbar freiliegende, grosse, runde, gleich zu beschreibende Zapfen finden, während andererseits ähnliche Gebilde von der Wand dieser Hohlräume entspringen und mehr oder weniger breit gestielt in dieselben hineinragen. Den Bau dieser Zapfen kann man einfach so be. schreiben, dass man dieselben als Adenome von Mammagewebe bezeichnet, bei denen die Entwicklung des Drüsengewebes diejenige des binde. gewebigen Gerüstes so vollkommen verdeckt, dass von demselben nur äusserst wenig zu sehen ist, ein Umstand, der noch dadurclı erhöht wird, dass das letztere sehr reich an jugendlichen Zellformen zu sein scheint. Trotzdem kann man erkennen, dass dasselbe sehr blutreich ist, denn man sicht an den mit Formalin gehärteten Präparaten nicht nur zahlreiche Capillaren, sondern es finden sich auch nicht unbeträchtliche Blutungen in das Gewebe hinein. 
So lange die Zapfen noch mit der Wand zusammenhängen, ist ihr Aussehen in der Regel etwas anders. Sie bestehen dann gewöhnlich aus einem ziemlich kernarmen bindegewebigen Grundstock, der an seinem, dem freien Lumen zugekelirten Ende aber eine ähnlicbe adenomatöse Tucherung erkennen lässt, wie wir sie bei den freiliegenden Zapfen beschrieben haben. Aber schon hier muss hervorgehoben werden, dass die Zellwucherung hier nicht immer ganz den strengen Drüsentypus wahrt, sondern dass die Grenzen mitunter so verwischt werden, dass man hier den Beginn cines Carcinoms diagnosticiren könnte. Der Stiel des noch mit der Wand in Zusammenhang stehenden Zapfens ist häufig am unteren Fnde so dünn, dass er wie das Product einer seitlichen Umschnürung aussieht. Das Bindegewebe, in das die eben beschriebenen Gebilde eingebettet sind, ist um die cinzelnen Hohlräume zunächst in Form einer sehr kernarmen concentrischen Schicht angeordnet, dann folgt ein etwas lebhafter von Kernen durchsetztes, aber durchaus nicht zellreiches Bindegewebe, um die jüngsten Alveolen und Drüsenwege herum findet sich immer eine reichliche kleinzellige Infiltration. Auch in diesem Bindegewebe kann man, wic vorhin, den Reichthum an feinen Gefässen constatiren.

Ich habe diesen Schilderungen wenig hinzuzufügen. Es handelt sich in dicsem Fall um ein sogen. intracanaliculäres Cystadenom, also um einen von den Tumoren, wclche als ziemlich selten gelten (K a u $\mathrm{f}$ mann), jedoch ron allen Beobachtern, welche ein einigermaassen reichliches Material hesassen, beschrielon worden sind. $K \ddot{z} n i g$, Sasse u. $\Lambda$. stellten ihn, wie sehon bemerkt, in einen scharfen Gegensatz zu den Cystadenomen der Mamma, und zwar bemerkt König in seinem Lehrbnch, dass es sich bei dicsen Arten ron Gebilden ganz in Gegentheil zum sogen. Cystadenom zweifellos um einen eehten Tumor handelte. Ich kann, wie gesagt, eiuen so scharfen Gegensatz zwischen beiden Frscheinungen nicht aufstellen und muss wieder auf das bereits vorhin von nir angezogene Beispiel der Netzepithelisirung hinweisen. Dort konnten wir ausdriieklich eonstatiren, dass sich das auf das Netz und die neugebildeten Zotten liniiberkricchende Fithel zu Drüsensehläuchen formirt und etwas. Aehnliches ist, grlaube ich, anch hier der Fall. Wenn wir schon treim Cystadenom gesehen haben, dalss sich das neugelildete und vermehrte J)rüsenepithel zu Zajfen wheht, wenn es zu Zottenwucherung ansteigt, so konnte man schon nach der angezogenen Analogie annehmen, dass es auch die Fähigkeit besitzen wïrde, sich auf diesen Zotten sellst zu Drïsenschläuchen anzuordnen und thatsächlich sahen wir bereits bei cinem l'räparate ron Cystadenom diese Erscheinungen (vgl. Fig. 1). I) as intracanaliculäre Cystadenom ist nun weiter nichts als eine Wiederholung dieses letateren Wachsthumstyous, d. h. a uch hier gerathen rie Epithelien in Wucherung, aber 
sie thürmen sich nicht übereinander, sondern sie bilden zottige, knollige Lrhebungen, die sich mit einem bindegewebigen Gerïst versehen, in das hinein sich nun aber wieder das in seinem Wachsthumstrieh noch nicht er. schäpfte Epithel stïlpt. Dass wir heim intracanaliculären Crstadenom nicht bloss die complicirte, adenomartige Zottenform, sondern auch die einfachen Gestalten finden, wird uns der nächste zu beschreibende Fall lehren. Wenn man in den intracanaliculïren Cystadenomen richtige 'Tumoren erblickt, so bleibt wieder schwierig zu erklären ihr multiples Vorkommen, wofür Sasse noch ein viel prägnanteres Beispiel liefert, als ich es im obigen Fall thun konnte. Bei der Annahme, dass es sich um einen ähnlich diffusen P'rocess handelt, wic bei dem gewöhnlichen Cystadenom, ist das multiple Vorkommen dieser kleinen Geschwülste, die theils in mikroskopiseher Feinheit erscheinen, theils bereits grob makroskopisch sichthar sind, nicht wunderbar.

Auszezeichnet ist freilich der zur Bildung des intracanaliculären Cystadenoms führende Process durch die Zühigkeit, nit welcher die Drüsenepithelien ilıre ursprüngliche Wachsthumsrichtung d. h. den Drüsentypus beibehalten. Es verräth sich letzteres auch in der Form der malignen Entartung, welche diese Tumoren eingehen kïnnen. Ich verfïge über 2 Beobachtungen von sog. Adenoma destruens mammae, einer Tumorform, welche, wic ich glaube, aus dem intracanaliculären Cystadenom alyzuleiten ist und ich will sofort noch über eine dritte Beobachtung herichten, welche nach meiner Insicht diesen Uebergano: zwischen einfachem intracanaliculärem Cystadenom und destruirendem Process zeigt.

Bezüglich des letzteren will ich nur vorausschicken, dass ich in diesem Fall die histologisch richtige Diagnose schon vor der Operation daraus stellte, dass sich bei der Patientin spontan, aber noch mehr bei leichten I)ruck eine ziemlich dünnflüssige blutirs-schleimige Flüssigkeit aus der Manilla entleerte. Ich hatte dieses Symptom schon bei der Frau G.1 kennen gelernt und es auf die Menge der im Tumor vorhandenen und in nächster Nachbarschaft grösserer, mit der Mamilla communicirender Hohlräume liegenden Gefässe bezogen. Ich labe dann auch gefunclen, dass Sasse in seiner Arbcit ebenfalls dieses Symptom der Blutung aus der Mamilla für die Diarnose der intracanaliculären Cystadenome verwerthet. Ausser dem gleich zu beschreibenden verfügre ich auch noch über einen dritten durch die Blutung aus der Mamilla auffälligen Fall, der zwar dureh die Operation nicht verificirt worden ist, der doch aber so geartet war, dass 
auch hier die Diagnose recht sicher erseheint. Es betraf diese Beobachtung eine ca. 111jälırige, eben verheirathete Frau, die zu ihrem ILausarzt gekommen war, weil sie scit einiger Zeit aus der linken Brustwarze blutete. Der sehr gewissenhafte und ansserordentlich tïchtige College hatte bei der Lntersuchung keincn Tumor gefunden, hatte aber die Patientin unter dauernder Beobachtung gehalten. Al, und zu, in der letzten Zeit tïglich, fanden sich Blutspuren in der Wäsche. Unurefülı nach 3: Jahren, nachdem die Patientin reboren hatte, wurde mir die Frau vorgestellt, nachdem auch schon der College bei ihr einen 'Tumor gefühlt hatte. Es fand sich ein haselnussgrosser, deutlich cystischer Tumor, der sich fast ganz durch Druck entlecr'n und eine dunkelrothe blutige, schr dünne Fliissigkeit zur Mamilla abfliessen liess. Leider wurde die ron mir vorgeschlagene Operation verweigert, doch zwcifle ich nach Anamnese und Befund nicht an der Diagnose intracanaliculäres Cystadenom, insofern ich eben das Abfliessen ciner relativ reichlichen, blutio verfärbten, aber schleimigen klebrigen Flüssirgkeit für diese Tumoren für charakteristisch halte, wenigstens habe ich bei anderen Geschwülsten der Manma, speciell niemals bei Carcinom einen derartigen reichlichen dbgangron blutiger Flitssigkeit beohachtet.

Einmal allerdings habe ich eine grössere mit einer ähnlichen Flüssigkeit gefuillten Cyste beim Careinom gesehen, aber da war das Verhältniss ungekehrt, es hatte sich der Krebs aus der Wand der primär angelegten Cyste sclbst entwickelt. Ich möclite nur noch bemerken, dass mir die relatir freie Communication, welche die Cysten des intracanalienlären Cystarlenoms mit der Aussenwelt halıen, doch gegen die Ansicht ron Sasso zu sprechen scheint, als ob diese Cystenbildumen nur lediglich durch Secretstauung in Folge Terlegung der Ansführungsgänge durch das in der Wand entstehende Adenom hervorgerufen seien. Dagegen spricht eben der Umstand, dass sich das Sceret, wie es scheint, in den weitaus meisten Fällen wenimstens theilweise auch spontan durch die Manilla entleert, so dass der Innendruck an und für sich gering ist.

Die Bildung des Cystenraumes geht nach meiner $\Lambda$ nsicht gleichzeitig mit der lintstehung des Adenoms vor sich durch Wachsthum der sich nebeneinander legenden Epithelzellen.

Fall II. Uebergang eines intracanaliculären Cystadenoms zum Carcinom bezw. destruirenden Adenom der $\mathrm{M}$ a $\mathrm{mma}$.

Frau St. 2 jo Jahr alt, aus gesunder Familie stammend, bisher immer gesund, hat 3 Kinder gehabt, die sie selbst gestillt hat, keine Mastitis; seit 6 Wochen bemerkt sie aus der linken Mamilla das Abfliessen von 
blutiger Flüssigkeit, die sowohl spontan tropfenweis hervorsickert, als sich auch auf Druck in etwas grösseren Mengen entleeren lässt.

Mittelgrosse, kräftige, gesund aussehende Frau, ziemlich corpulent, innere Organe gesund, menstruirt nicht, Unterleibsorgane ohne Befund. In der linken Mamma findet sich dicht neben der Mamilla ein etwa baselnussgrosser, harter, verschieblicher Tumor, nicht deutlich gegen die

Fig. 6.

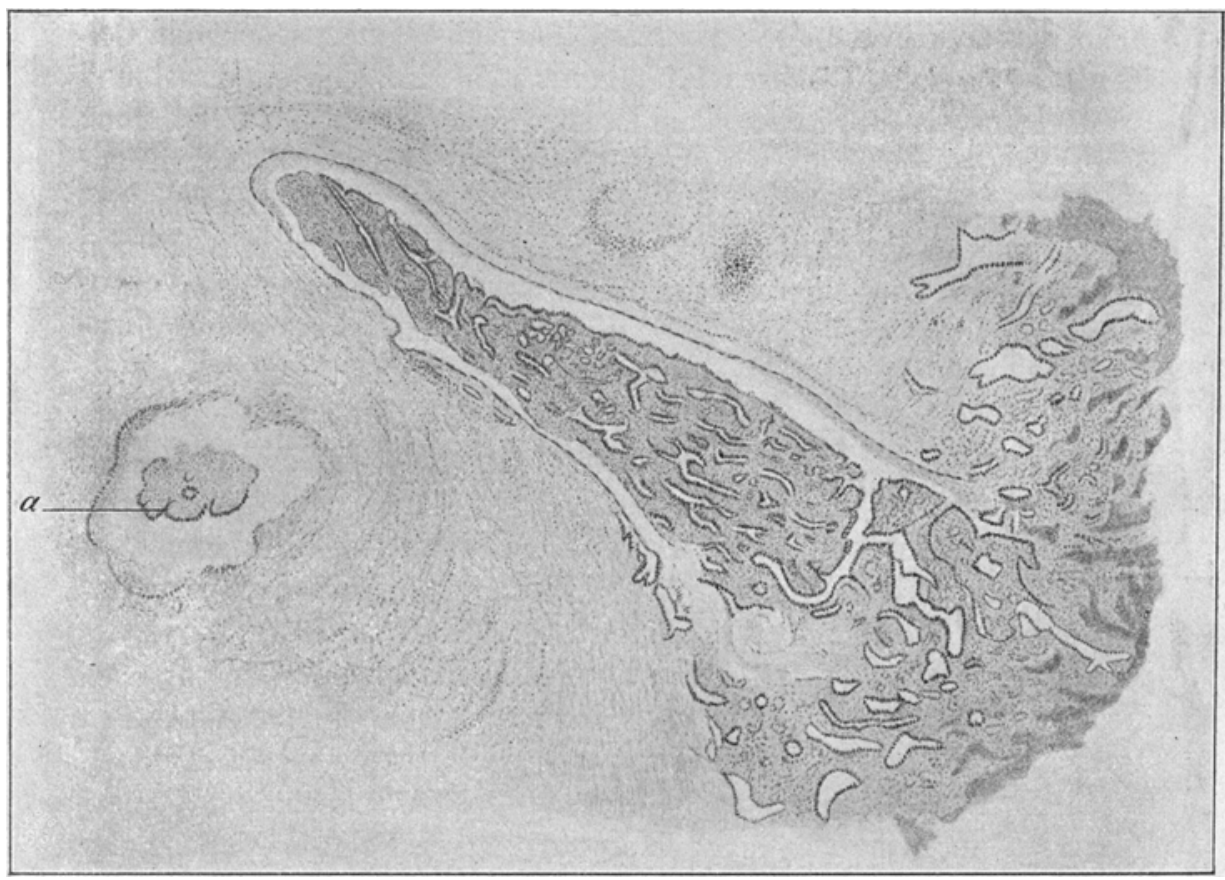

Grosser intracanaliculïrer Zupfen, dessen Stiel bereits von Drüsenwucherungen durchbrochen ist. Bei $a$ isolirt liegeuder, mit grossen Epithelien bekleideter ,blattartiger" Zapfen.

Umgebung abgrenzbar, nicht mit der Haut verwachsen, auf Druck nicht schmerzhaft. Drüsenschwellungen nicht vorhanden. Bei Druck auf den Tumor fliessen aus der Mamilla einige Tropfen blutiger Flüssigkeit von schon beschriebener Beschaffenheit. Amputation der Mamma mit Eröffnung der Achselhöhle, in der Drüsen nicht gefunden werden. Der fragliche Tumor ist auf dem Durchschnift deutlich gegen die Nachbarschaft abgegrenzt, ist grauweiss, lässt mehrere feine mit Blut gefüllte Spalten erkennen.

Wenn ich eine Beschreibung der histologischen Structur dieses Tumors geben wollte, so musste ich zunächst, was ich ther den vorigen Tumor G., gesagt habe, Wort fur Wort wiedcrhohlen. 
In der That ist der Tumor St. 2 in der Hauptsache ganz das Abbild des vorigen, nur vielleicht mit dem Unterschicde, dass das Bindege. webe bei St.2 etwas zelliger und der ganze Tumor etwas blutreicher war, als G.1. Aber es bestcht allerdings ein cardinaler Unterschied und das ist der, dass die eigenthumliche Drüsenentwicklung, die wir bei G.। auf die intracanaliculären Zapfen besehränkt fanden, sieh hier auch auf

lig. 7 .

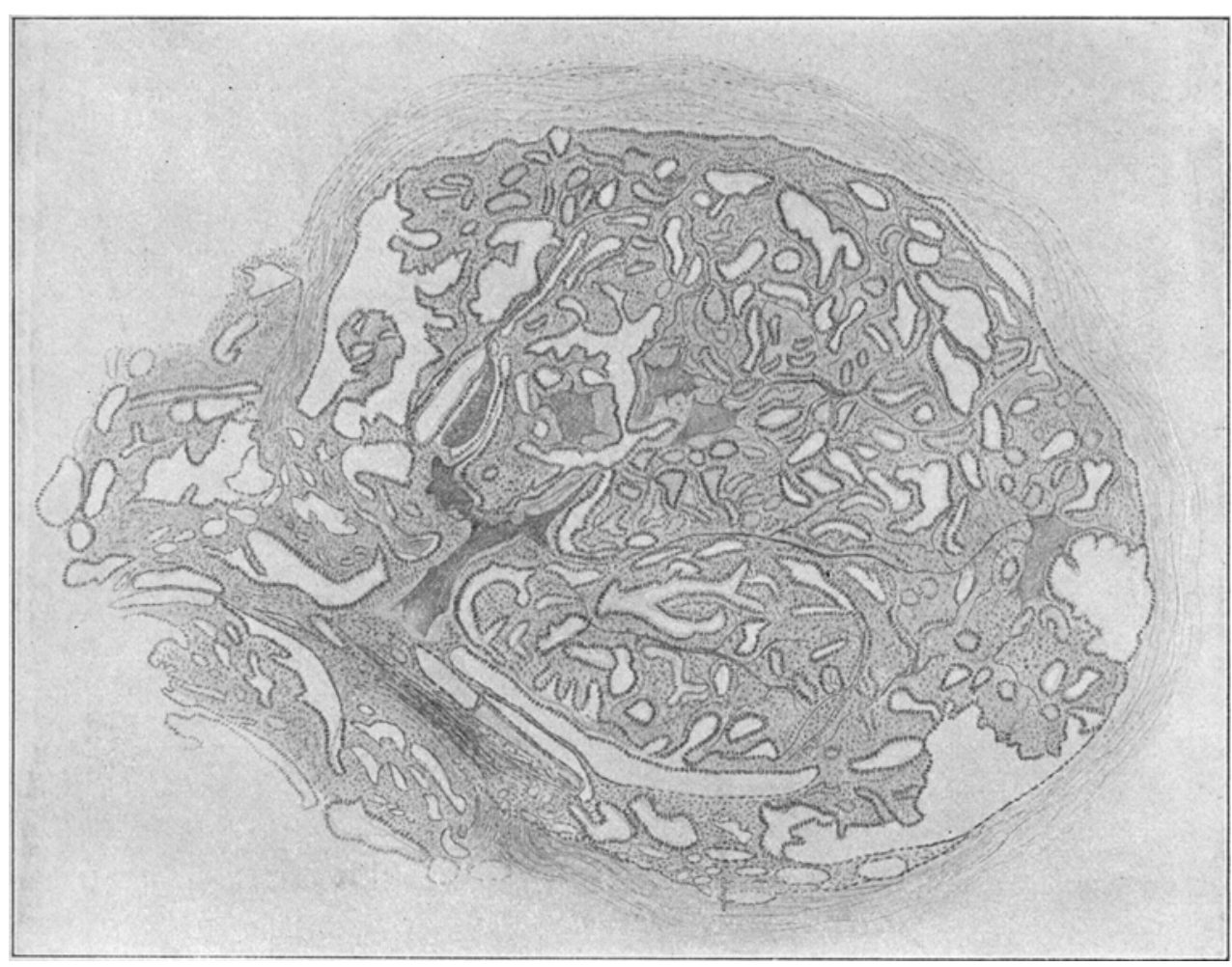

Ius demselben Prijparat wie Fig. 6. Grosser Hohlraun von einem Rankenwerk von Zotten durchzogen, welche durch ihre viclfache Theilung und Verschlingudg Drüsen vortänschen.

das intercanaliculare Bindegewebe fortpflanzt und $z$ war offenbar so, dass diese Drüsenentwicklung in dem wandständigen Zapfen so lebhaft vor sich geht, dass sie denselben durchdringt, bis sie den Stiel crreicht, diesem eine Zeit lang folgt, ihn auch iiberschreitet und vun in das zwischen den Dritsencanälen gelegene Bindegewebe eindringt. Ausserdem finden sich in diesem Tumor aber noch Stellen, die ein manz anderes, uns bisher nicht bekanntes Bild darbieten. Diese Stellen sind folgende: es sind runde, von mässig breiten concentriseben Bindegewebslagen ungebene 
Hohlräume, die durchzogen sind, von einem ganzen Gewirr von vielfach sich verzweigenden und mit einander verwachsenen Bindegewebsfasern, die selten in Form etwas dickerer Stränge, meist in Gestalt feinster und zierlichster Fibrillen den Hohlraum durchziehen und ihn in ein ganzes System feiner Maschenräume theilen, die zuweilen spaltförmig und poly.

Fig. s.

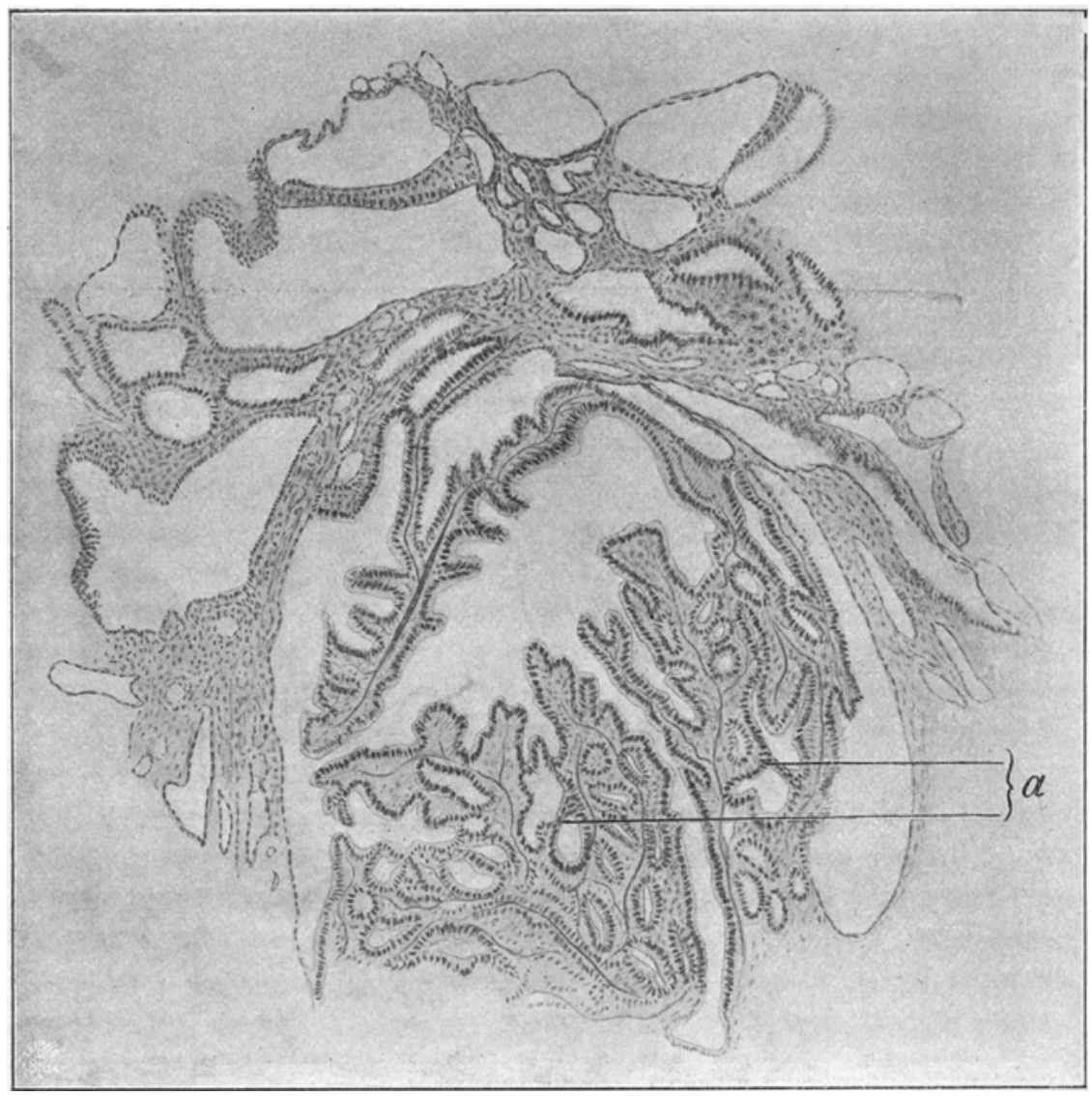

Dasselbe Präparat wie Fig. 7. Beginnende Raukenbildung. Bei $a$ beginnen benachbarte Epithelsprossen mit einander zu verschmelzen.

gonal, mitunter aber fast rund erscheinen. In den Fibrilleu sind bei van Gieson'scher Färbung dunklere Striche zu sehen, die Gefässen zu entsprechen scheinen. Nach beiden Seiten hin sind die Fibrillen besetzt von einem sehr schön ansgebildeten bohen Cylinderepithel, dass so wobl geordnet erscheint, dass das ganze Bild den Eindruck macht, als habe man es hier mit einem Quersclsnitt durch mannigfaltig gestaltete, eng an- 
einander liegende Drusenschläuche zu thun. Derartige Hohlräume finden sich nun, durch lockeres Bindegewebe getrennt, ziemlich zahlreich bei einander. In einigen aber von ihnen ist das Epithel so vermelurt und das Bindegewebsstiltzgerust tritt so zurlick, dass, wälırend die Zellen sich gleichmässig abplatten, diese Stellen einfach aussehen wie Krebsalveolen; allerdings respectirt dic Neubildung an diesen Stellen immer die ursprünglichen Grenzen insofern, als die bindegewebige Grenzschicht niemals durch. brochen war.

Nicht ganz leicht ist die Frklürung fïr diese Erscheinungen zu geben. Nach meiner Ansicht kann es sich hierbei aluer bloss um zwei

Fig. !.

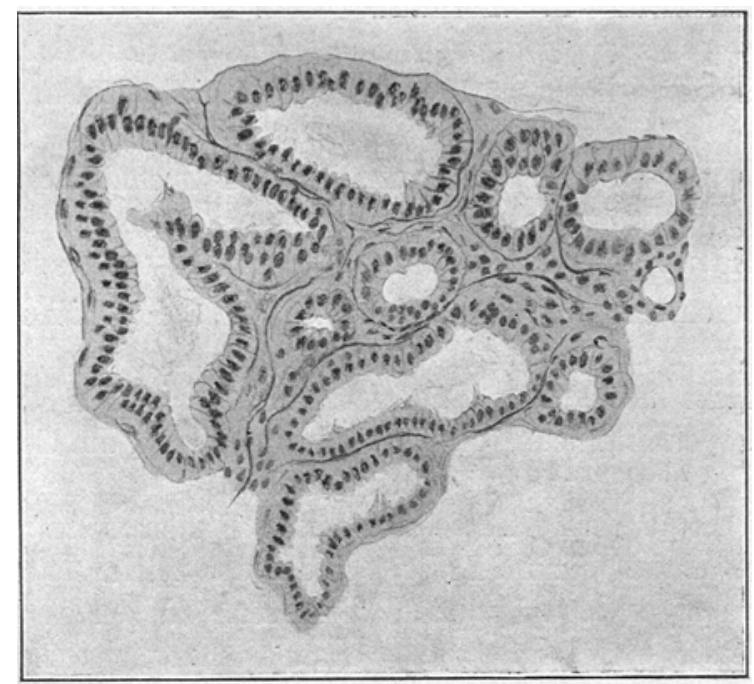

Dieselbe Stelle wie Fig. 7 bei starker Vergrössermng.

Dinge handeln, entweder verdanken diese zuletzt (Fig. $\bar{\tau}-9)$ beschriebenen Bildungen ihre Entstehung der drüsenförmigen Epithelwucherung, wie wir sie bei I)urchlorechen des Stieles der in die Cysten hineinragrenden Zayfen beolachtet haben, d. H. nachdem der Stiel durchbrochen ist, bilden sich immer zahlreichere Drüsenformen, wobei ilıre hindegewebigen Zwischensepten zusammenrïcken - dagegen spricht aber die ausserordentlich regelmässig runde Begrenzung des Gesammtherdes oder die Gebilde entstehen ron vornherein in Cysten in zweierlei Wreise und zwar 1. dadurch, dass in den Innenraum derselben massenlaft kleine Zotten lineinwuchern, die sich theilen und mit einander in der Weise verwachsen, dass nachträglich das eigenthïmliche binde- 
gewelige Maschenwerk herauskommt, das natïrlich auf beiden Sciten d. l. nach dem freien Lumen der Gerwebsmaschen zu, ron Cylinderzellen besetzt sein muss: - ich glaube derartig- die Anfünge des Processes melrfach in meinen Präjaraten wesehen zu haben - und zweitens handelt es sich wohl auch vielfach bei diesen Processen wieder um secundäre Drüseneinstïlpungen in die gewucherten Kotten, also unı wirkliche intracanaliculäre Cystadenome.

Im Lebrigen nı̈̈chte ich den Bau des beschriebenen Tumors durch die Abbildungen Fig. o bis 9 illustriren, von denen Fig. 6 das Durchbrechen des Stiels eines intracanaliculären Adenoms durch die Drüsenwucherungen zeigt, während Fig. 7 bis 9 jenes Rankenwerk ron Bindegewebe mit Cylinderzellen besetzt im Cystenhohlraum zeigt. Iuf Fin. 6 erscheint bei a noch ein besonderer Zellconılex, es ist cine mit mächtigen Zellagen bedeckte frei in einen Hohlraum ragende \%otte.

Interessant werden dic intracanaliculären Cystadenome nun aber wie schon benerkt, ferner iturch ihre nahen Beziehungen zum destruirenden Adenon der Mamma (vergl. II ̈̈ckel 1), Sas se).

Von diesen destruirenden Adenomen habe ich bisher 2 operirt, aus deren Vorgeschichte ich nur Weniges anzuführen habe. Es handelt sich beide Male un Frauen mittlerer Jahre, das eine Val um eine 14 jährige, unverheirathete Nullipara, das zweite Mal um eine 12 Jahre alte Frau, die 10 mal gehoren hatte. Beide Framen waren vorher gesund gewesen, die verheirathete hatte ihre Kinder selbst restillt, sie hatte niemals eine schlimme Brust, bei der unverheiratheten Fran I.: lestand seit einigen Monaten eine Verhärtung in der rechten Brust, die die Patientin ursprünglich aus Furcht verheimlicht hatte, bis sich Schmerzen cinstellten, welche die Patientin zum $\Lambda$ rzt führten. Bei der zweiten Frau 13. \& war vor $21 \%$ Ifonaten in acliten Monat der letzten Graviditäit ein Knoten in der rechten Brust benerkt worden, welcher schmell wuchs, während nach und nach auch Knoten in der Achselhöhle sich bemerkbar machten. Bis zun Ende der Schwangerschaft erreichte die Anschwellung in der Brust eine enorme Grösse, doch stillte Patientin noch über \& Wochen ihr Neugeborenes, che sie nach Breslau kanı. Nach der Enthindung soll der Tumor wieder kleiner geworden sein.

Für die Untersuchung boten beirle Tumoren ein etwas verschiedenes Bild. Bei $\mathrm{I}_{2.3}$ ist die rechte Brustwarze etwas eingezogen. Die IIamma ist in einen reichlich fausterossen derben T'unor verwandelt,

1) Hacekel, Jangenbeck's Arehir. BH. XlXII. 
der mit der L'nterlage nicht rerwachsen ist. Die ILaut über demselbeu ist leicht geröthet, gespannt und nicht faltbar. In der Achselhöhle sind 2 kleine, derhe I)rüsen zu fühlen. Bei Fran 13.4 fand sich die rechte Brust in einen mächtigen Tumor verwandelt, der nahezu mannskopfgross, mit der ödematïsen Ilaut ziemlieh innig verwachsen war, wiihrend er sich gleiclifalls nur uit dem Pectoralis zusammen rerschob. Die Mamilla war nieht cinqezogen, in der dehselhöhle war cin mächtiges Drüsenpacket zu fühlen, die Schlïsselbeingruben waren frei.

Beide Tumoren wurden, wie ïblich, im Zusammenhang mit einem grossen Hautstïck und dem grösseren Theil des Musculns pectoralis major, sowie dem Fett der Aclsselhöhle entfernt. Das subcutane Fettgewebe erwies sich in Fall B.ı als üdematös durehtrïnkt, das Messer gerieth mehrmals in crhaltenes Mammagerwebe, aus welchem Milch abfloss. Ileilung erfolgte in beiden Fällen glatt. Patientin $I_{0.3}$ ist jetzt nach über 3 Jahren recidivfrei. Bei Patientin B.4 hat sich nach , Jahren ein Recidiv in der Xarbe und in der Supraclaviculargrube entwickelt, das operirtwurde, seitem bin jeh ohne Nachricht ron der I'atientin, doch fürehte ich, dass ihr Schicksal sich nicht wird haben athalten lassen.

Die Besichtigung der Präparate ergab Folgendes: die $\mathrm{Namma}$ bei L.3 war in einen gleichmässigen Tumor verwandelt, von fast rein weisser Farbe und markigem Gefüge, in dem man Structurcu makroskopisch nicht zu erkennen vermochte. Nach allen Seiten gut abgegrenzt, war er mit Haut und Muskelfascie nicht verwachsen. Inmitten der Gesehwulst fand sich plötzlich ein centraler, circa kastaniengrosser rundlicher Kern, welcher durch seive Färbung und, scine zierliche Zusammensetzung sich lebhaft von den gleichmässigen Weiss der Umgebung unterschied. Diese Partie hatte auf dem IJurchschnitt eine fast kreisrunde Form, deren Begrenzungslinie aber nieht gleichmässig verlief, sondorn zahlrciche wellen-, bezw. bogenfürmige Ausbuchtungeı zeigte.

Die Farbe diescz Abselnittes wechselte von einem deutlichen Grau. schwarz in den Grenzbezirken bis zu einem weisslichen Grau der centraleren Partien. Ueberall war aber zu erkennen, dass der Farbstoft streifen, bezw. punktförmig angeordnet sein musste, wenigstens sah man zahlreiche dunkel pigmentirte Leisten durch das Gebilde hindurchziehen, wodurch es ein eigenthümlich drissenförmiges Ausseheu erhielt. In den Lymphärüsen dieses Falles zeigten sich Tumorcnmetastasen, die sich makroskopisch in nichts von dem Aussehen gewöhnlicher Krebsmetastasen unterschieden.

Der zweite Tumor bot auf seinem Durchschnitt ein selir buntes Bild, das uns in seiner Deutung und Beschreibung aber keine sehr grosse॥ Schwierigkeiten mohr darbietet, weil es ziemlich genau dic Verhältnisse der vorigeu Geschwulst wiederholte, nur mit dem Unterschiede, dass sich das, was dort in einfacher Bildung vorhanden war, hier in manuigfacher 
Wiederholung präsentirte, d. l. die Geschwulst bestand aus einer grossen Anzahl von rundlichen, verschieden grossev, dunkel pigmentirten, drüsenartig aussehenden Knoten, welche in eine derbe, mehr weissliche Grundmasse eingebettet waren. Thatsächlich entsprach Form, Anordnung und Färbung der einzelnen Bildungen ziemlich genau dem vorhin beschriebenen pigmentirten Knoten in der vorigen Brustgeschwulst, nur eben mit dem Unterschied, dass hier ein Theil der Knoten bereits erweicht und zerfallen war. Die Begrenzung dieser Knoten war meist eine sehr scharfe und nur an seltenen Stellen schien ein Durchbruch in das umgebende Grundgewebe stattgefunden zu haben. Dieses letztere unterschied sich allerdings etwas von demjenigen im vorigen Falle: Während nämlich dieses durchaus gleichmässig, homogen erschienen war, konnte man in jenem eine Anzahl streifiger, wahrscheinlich bindegewebiger Zuge erkennen, in welchen eiue Anzahl weisslichgelber Stippchen auffielen. Nur an den Stellen, wo die Knoten in das Grundgewebe durchbrochen waren, zeigte letzteres eine ziemlich bomogene derbe Beschaffenheit. Im Ganzen war die Consistenz dieses Gewebes iberhaupt fest und derb, nirgends erweicht, offenbar war es sehr gefässarm. Die Achseldrüsen dieses Falles waren fast ganz in markige rein weisse Tumoren verwandelt.

Ich muss gestehen, dass ich nach dem makroskopischen Aussehen der durchschnittenen Tumoren nicht in der Lage war, eine bistologische Diagnose zu stellen, da mir ähnliche Bilder bisher nicht bekannt waren. Mit einiger Spannung ging ich daher an die mikroskopische Untersuchung, zu welcher zuerst Schnitte aus den scheinbar drüsigen Theilen verwandt wurden. Wie erstaunte ich aber, als ich in beiden Tumoren genau dieselben Verhältnisse antraf, wie ich sie im Kleinen schon in Fall St.2 gesehen hatte; diese Theile der Tumoren nämlich erwiesen sich zusammengesetzt aus einem System von Cysten, die erfüllt waren mit einem vielfach verzweigten, feinen, masehenbildenden und mit hohen Cylinderzellen besetzten Bindegewebe, welches durch seine Anordnung und dendritischen Verzweigungen ganz den Eindruck eines Systems von Drtisenschläuchen hervorbrachte. Diese runden, zusammengesetzten, drtlsenähnlichen Bezirke waren verschieden gross. Erreichte ein Theil von ihnen eine solche Grösse, dass er bei schwacher Vergrösserung bereits das Gesichtsfeld iberragte, so waren dieselben doch stellenweis so klein, dass sie dicht gedrängt in einem Gesichtsfeld lagen und oft von ihnen 6-10 gezählt werden konnten. Sie waren von einander dann getrennt durch stellenweis sebr stark kleinzellig infiltrirtes Bindegewebe, das zunächst die einzelnen drusenähnlichen Gebilde concentrisch umschloss und sich dann zwischen denselben in Form langfasriger Fibrillen ausbreitete. Die so beschaffenen Stellen erweckten einen exquisiten Drüsenanschein und hätten bei oberflächlicher Betrachtung als Schnitte aus einem drusigen Organ, z. B. den Speicheldrusen gelten können. Den Beweis dafur, dass die drusenartigen Bildungen aus einer Sprossung von Cylinderzellen bekleideten Bindegewcbe innerhalb vou Cystenräumen ihre Entstehung verdankteı, konnte man darin erblicken, dass an sehr vielen Stellen noch nicht dieses enggedrängte Rankenwerk vorhanden war, welches die ganze Cyste ausfullte, sondern dass sich durch den Hohlraum an vielen Stellen nur ein spärliches Gitterwerk hindurcbzog, welches die Unter- 
scheidung der einzelnen Abtheilung leicht ermöglichte. Die Innenwand der Cyste selbst zeigte in der Regel keinen Fpithelbelag. In den bindegewebigen Septen des Hohlraumes war spärliches scholliges Pignent vorhanden, extracellulär liegend. Ebenso fanden sich in den maschenförmigen Hohlräumen zahlreiche Blutaustritte, welche, wie es schien, wesentlichen Antheil an der dunklen Färbung der Tumoren ausmachten. Die kleinen Cysten zeigten die Verhältnisse am deutlichsten. Hier sah man

Fìr. 10.

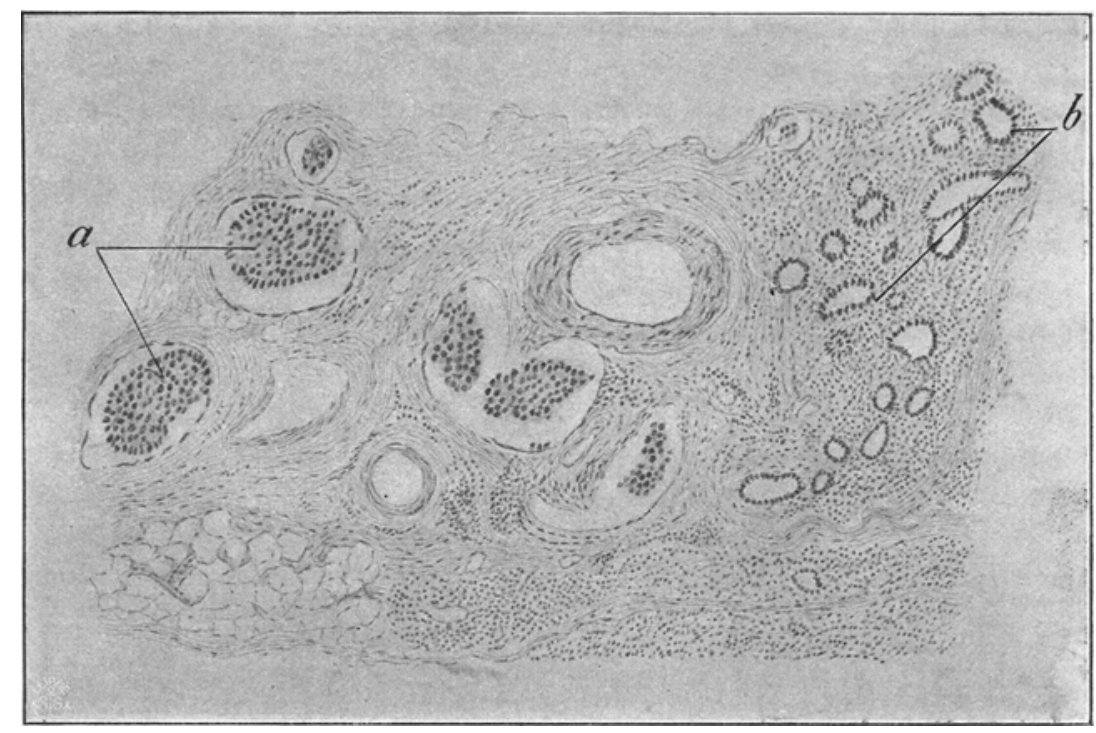

Ius dem Zwischengewebe eines destruirenden Adenoms. Man sieht auch hier Tumorelemente, und zwar entweder in Form kolbjger ,encystirter" Zapfen ( $\prime$ ) oder neugebildeter Drüsen (b).

zuweilen nur eine einzelne mehrfach getheilte Sprosse in das Lumen hineinragen oder man traf einen Hohlraum, in welchem ein kolbiges Gebilde freilag, mit grossen Zellen bekleidet, in dem ich einen Durchschnitt einer freiliegenden Zotte vermuthe. Interessant war die Untersuchung des Zwischengewebes. Dasselbe erwies sich in beiden Fällen verschieden gestaltet, in dem Falle L. 3 wies es im Grossen und Ganzen nur wenig veränderte Mammabestandtheile auf, welche in ein derb faseriges Bindegewebe eingelagert waren. Es glich so ziemlich einer senilen Mamma mit leichter Erweiterung der Drusenschläuche. Das dieselben umgebende Bindegewebe überwog mächtig an Masse und war selır kernarm. Anders war es im Falle B. .. Auch hier gab es Stellen, welche dem Gewebe einer senilen Brustdrüse vollkommen glichen. Das war aber der kleinste Abschnitt. In der uberwiegenden Masse war in diesem Falle auch ausserhalb der frilher beschriebenen Knollen das Gewebe init Tumorelementen 
durchsetzt und zwar fanden sich dieselben in mehreren verschiedenen Anordnungen, einmal sah man zwischen den Bindegewebsbündeln wieder exquisite Drulsenformen, ohne dass dieselben aber etwa in ihrer Anordnung einem Complex normaler Alveolen oder Drüsenscliläuche entsprochen hätten, so dass sie wohl als Neugebilde angesehen werden mussten. In anderen Fällen sah man im Bindegewebe einfach runde, epithellose oder, wie es schien, endothelbekleidete Hohlräume, in welchen frei im

Fig. 11.

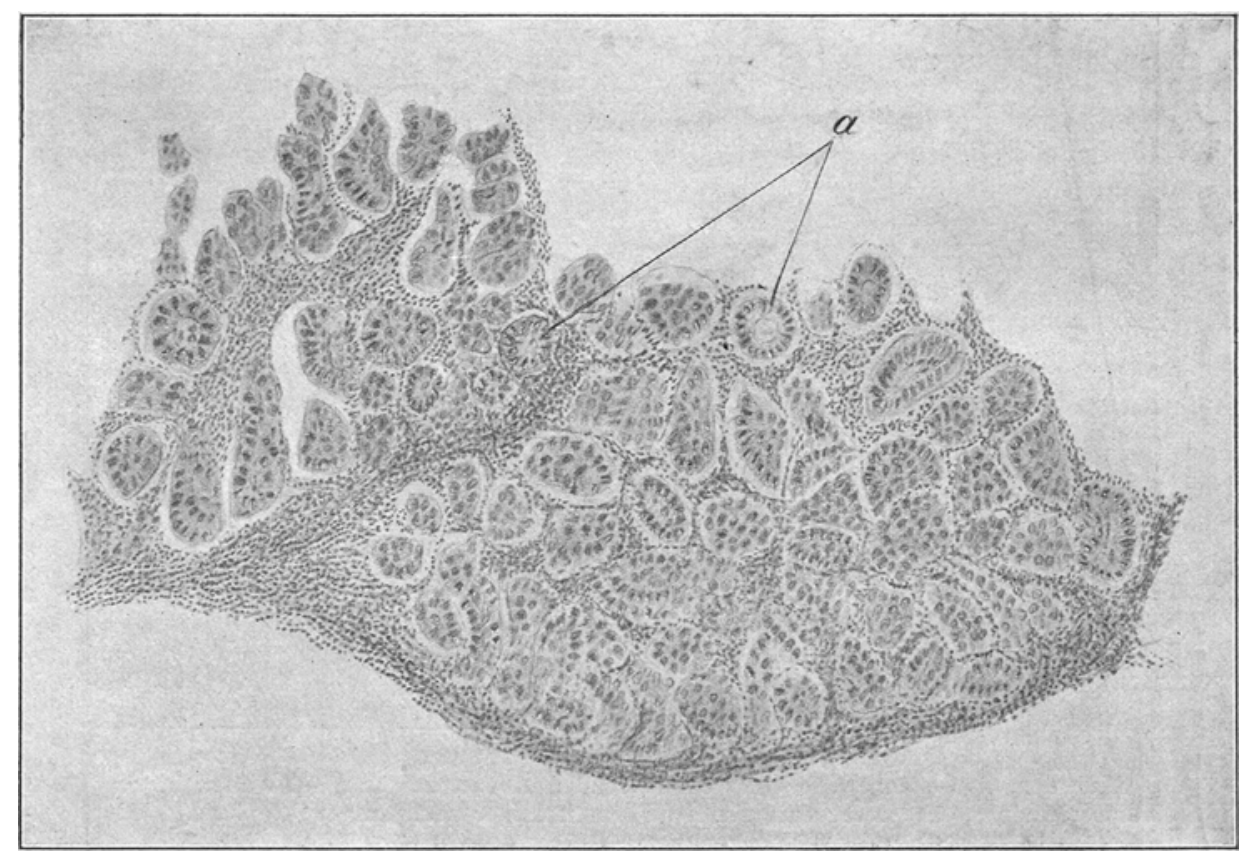

Drüscumetastase eines destruirenden Adenons. In cler Anordnung der Epithelien ist die Inrïsenforu beibehalten.

Lumen liegend blattartige (blumenkohlartige) Büschel eug aneinander gelagerter, ziemlich grosser Zellen mit grossen Kernen zu finden waren. Nicht immer konnte man in den Büscheln ein bindegewebiges Gerilst nachweisen, aber an anderen Stellen war dasselbe deutlich und wan konnte wohl nicht irren, wenn man in diesen Gebilden die Durchschnitte ähnlicher Zapfen erblickte, wie bei Fig. 6. Diese blattartigen Büschel entsprachen den Stellen, wo man mit blossem Ange bereits die cigenthümlichen weisslichen Stippchen zwischen den Bindegewebsfalten geseben hatte. Noch gab es schliesslich Stellen, welche einen exquisit carcino. matösen Bau darboten. Makroskopiseh waren dieselben nicht zu erkennen, wenn sie auch ein etwas gleichmässigeres Aussehen darboten als das abrige Zwischengewebe. Jedenfalls komnte man niclit immer darauf 
rechnen, von vornherein cine solche Stelle finden zu köınen, um sie zum Zwecke der mikroskopischen Untersuchung herauszuschneiden. Eigenthümlich war, dass die zu mächtigen Lagern angeordneten Carcinomzellen zum grossen Theil der Nekrose verfallen waren, welche bauptsächlich

Fig. 12.

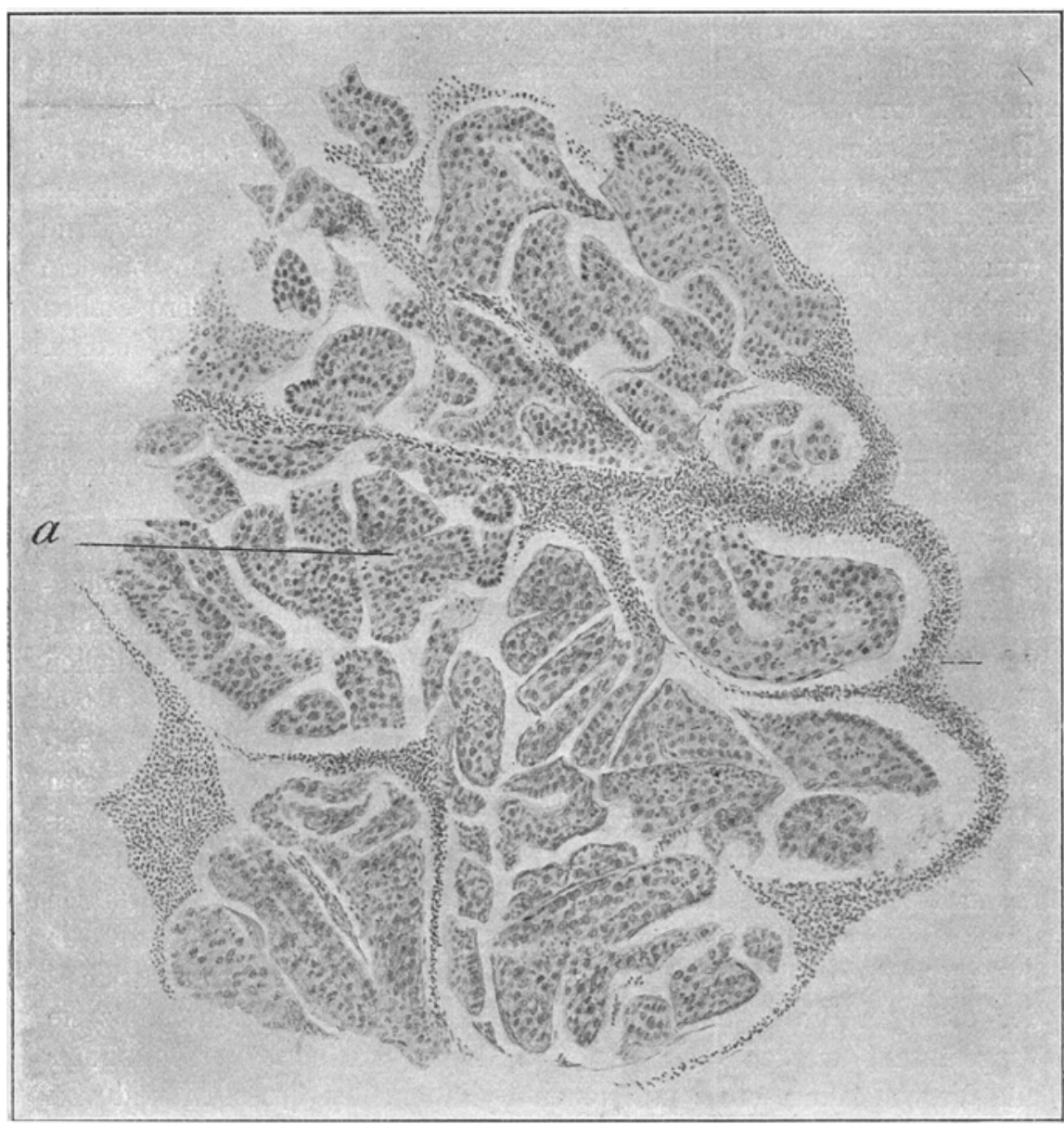

Drüsenmetastase eives destruirenden Mammuadenoms. Die Anordnung der Epithelien entspricht mehr dem Carcinomtypus, stellewweise sieht man noch $(a)$ ïhnliche Zapfen, wic im laupttumor.

die centralen Partien ergriffen hatte und eine Randzone meistens frei liess. Wenn man nicht genau beobachtete, konnte man die letzteren dann für schlauchartige Zellzüge halten, welche sich durch das Gesichtsfeld zogen und dem ganzen Präparat ein eigenthilmlich an ein lindotheliom 
erinnerudes Gepräge gaben. Zweifellos aber waren diese Bildungen an und für sich nur Kunstproducte und durch den Zerfall der mittleren Zellpartien bedingt.

Noch ein Wort muss ïber die Drüsen in beiden Fällen gesagt werden. Wie bereits bemerkt, boten dieselben makroskopisel nichts, was sie von einer Carcinommetastase in einem gewöhnlichen Fall von Mammacarcinom untersehieden hätte. Mikroskopisch war die Sache wanz anders. Im Falle L.: war die Lymphdrüse vollkommen erfüllt mit Tumormassen, welche sich auf den Durchschnitt in Form von Drüsenschläuchen, die aus Cylinderzellen gebildet waren, präsentirten. In dem Fall B.t waren ähnliche Bildungen vorhanden, doch trafen wir auch hier wieder jene Zellbuischel von Blattform, deren Rand von deutlichen Cylinderzellen gebildet war, die wir schon in dem Zwischengewebe dieses Tumors beschrieben haben. Andere Stellen der Drüse zeigten den gewöhnlichen Bau eines Carcinoma simplex. Die Entstelung dieser destruirenden Adenome ist nach meiner Insicht so zu verstehen: Sie stammen ab von den intracanaliculären Cystadenomen. Wir sahen in ihnen eine Anzahl ron Hohlräumen mit eigenthïmlich blumenkohlartigen Epithelhaufen. Das sind offenbar freie, in das Lumen eystisch erweiterter Drüsenschläuche cinspringende Zottengeschwïlste, wie wir sie von den intracanaliculären Cystadenomen her kennen. Im übrigen crhalten die destruirenden Jrlenome ihr charakteristisehes Gepräge ron den eigenthïmlichen Drüsenformen, die ilıren Hauptbestandtheil ausmachen. Ein 'T'heil von diesen sind wohl echte Drüsenbildungen (vergl. Fig. 10), welche entstehen, indem sich auf intracanaliculären Zotten-Geschwülsten Drüsen bilden, die auch den Sticl durchbrechen können (vergl. den Lebergangsfall S. 535) und in das benachbarte Bindegewebe einwuehern, während die in letzterem zu beobachtenden Drïsen auch häufig entstehen mögen durch einzclne in die Nachbarschaft verschleppte Zcllen cbenso wie die drüsenförmigen Metastasen in den Lymphldrüsen. Der grössere Theil der driisigen Bildungen ist aber insofern ein Kunstproduct, als sie vorgetïuscht werden oder entstehen durch viclfache Verschlingung und Verwachsung eines mit hohen Cylinderzellen besetzten und von der Wand von Cysten entspringenden Bindegewebes, wobei es rorkommen mag, dass dieses Rankenwerk das Cystadenom durchbricht und in das Zwischengewebe einwuchert. Die Entwicklung dieses Rankenwerkes sehen wir auel in dem Fall S. 535, den wir als Uebergang $z$ wischen einem intracanaliculären Cystadenom und destruirendem $\Lambda$ denombezeichneten, wir fanden aber auch bei den einfachen Cystadenomen (Schimmel- 
busch) Analogien hierzu in der Form der in das Cysteninnere hineinwuchernden Epithelzotten. Es zeigt dies also, wie nalle alle diese Processe mit einander verwandt sind. Trotzdem steht das destruirende $\Lambda$ denom dem intracanaliculären Cystadenom näher, denn es ist wie dieses ausgezeichnet durch die Zähigkeit, mit weleher die wuchernden Zellen ihren Drüsentypus festhalten, wobei sich freilich, wie Fall B.4 lehrt, Ausnahmen, atypische Wucherung, d. h. Lebergänge in das Carcinom finden.

Was sich in den Drüsenmetastasen findet, das hängt von den verschleppten Zellen ab. Gehörten dieselben zu den Zellen mit zwar unendlichem Wachsthumstrieb aber unveränderter Wachsthumsrichtung, so erhalten wir richtige Irüsenformen in den Metastasen oder jene bättrigen, zottigen Gewächse auch in den Lymphıdrïsen; war auch die Wachsthumsrichtung bereits pathologisch, so zeigt auch die Drïsenmetastase bercits das Bild des Carcinoms.

Wir fanden also:

1. Cystadenoma Schim melbusch: Epithelwucherung bis zum völligen Ausgruss der Alveolen, Epithelpapillen mit und ohne Bindegewebe, drüsentragende Zotten; Lebergang zum Carcinom.

2. Cystadenoma intracanaliculare. Dribenbildende (adenomartige) multiple Geschwülste von einer Cystenwand entspringend. Der Stiel kann von den Drüsenwucherungen durchbrochen werden, Lebergang zum $\Lambda$ denoma bezw. Adenocarcinoma destruens. Dicse Uebergangrsformen und das destruirende $\Lambda$ denom noch weiter ausgezeichnet durch ein eigenthümliches Rankenwerk epitholtragender Zotten. Icetztere in l'arallele $\%$ setzen mit den Zotten des Cystadenoms (Sch.)

Es sind, wie man vielleicht aus der Beschreibung, mehr jedenfalls aus den Zeichnungen sieht, zwischen diesen Krankheitsbildern so vielfache Uebergänge vorhanden, dass ich dieselben als grenetisch zusammengehörig betrachte, jedenfalls das Cystadenom nach Schimmelbusch und die multiplen intracanaliculären Cystadenome nur als versehiedene Typen desselben Processes auffasse, eines Processes, welcher, wie schon von vielen Autoren hervorgehoben worden ist, grosse Aehnlichkeit zeigt mit Erkrankungen, wie wir sie an einem der Mamma verwandten Organ kennen, dem Ovarium. In der That werden jedem, der z. B. die ansezezeichnete Darstellung dieses Capitels von l' fa nncnstiel im Handbuch ron Veit liest, die Vergleichungspunkte sich aufdrängen. Ich halte es daher für angemessen, sich auch in der Nomenclatur an diese Vorbilder anzulehnen und schliesse mich denen an, welche den Namen Cystoma mammae für das Cystadenoma nach 
Schimmelbusch eingeführt wissen wollen, worunter ich allerding: auch noch die multijlen intracanaliculären Cystadenome beyreife. ${ }^{1}$ )

Die Erklïrung wird also folgendermassen lauten:

Das Cystoma mammae ist cine häufig unter dem Bilde schuhwois cinsetzender Entziindungen verlaufende und zu multiplen Cystenbildungen in der Jammasubstanz führende Erkrankung, wclche unabhängig von überstandenen Gehurten Individuen der mittleren Jalıve befällt, sehr häufig in beiden Brüsten greichzeitig oder nach cinander auftritt und charakterisirt ist durch eine Wucherung ron Drüsenepithelien, die entweder in Form trleichmässiger Ausfïllung der Alveolen und Schläuche, theils in Gestalt multipler papillärer Excrescenzen und Epithelzotten auftritt, ja auch zur Entstehung alenomähnlicher intracanaliculär gelegener Gebilde führt. Durch Wueherung und Zerfall der Epithelien sowohl wie dureh Secretion der überlebenden bilden sich dic Cysten, deren Epithelien sich bei weiterem Wachsen der Cyste abplatten und ganz verloren gehen können. Eine Betheiligungr des Binderewebes iul Sinne einer Entzündung ist vielfach vorhanden, tritt aber an Bedeutung gregrenüber der Epithelvermehrung zurück. Die Erkrankung hat die Neigung, zur malignen Fntartung überzufülıren, die entweder in Form eines gewölnlichen Carcinoms oder eines sorrenannten de strurenden Mammaadenoms auftritt. Welehe von den beiden letzten Tumorarten erscheint, hängt davon ab, in welchem Grade die vorhaudenen Epithelzellen ihre normale Wachsthumsrichtung' beibehalten haben. Auch die Drüsenmetastasen zeigen je nach der $\Lambda$ rt der rer. schleppten Zellen mehr den carcinomähnlichen Charakter oder melır denjenizen des $A$ denoms.

Zu den obigen Untersuchungen habe ich einen Theil der Fälle benutzt, welche ich in Vertretung von IIerm Geheimrath v. Mikulicz als consultirender Chirurg im hiesiwen Fränkel'schen Hospital ope-

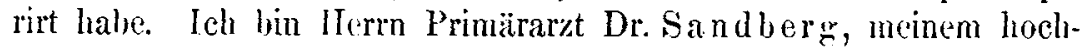
verehrten Freunde, für die Erlaubniss zur Publication aufs wärmste verbunden.

Eluenso fühle ich mich Fräulein stud. med. Elise Ebstein für die äusserst sorgfältige Ausfïlıung der zum Theil sehr mïhsamen Zeichnungen zu lebhaftestem Danke verpflichtet.

1) So ähnliche Bilder beide Procesac auch häufig ergeben, so ist doch rorläufige das Fibroadenom in seinen verseliedenen dbarten (intracanaliculäres Fibrom, Cystosareoma phyllodes) vom (yotadenoma, bezw. Cystomat mammite zn tremnen, weil der I'rocess der Ejpithelvermehrung hier wegenïber der Betheiligung des binclegewelos zurïcktritt. 


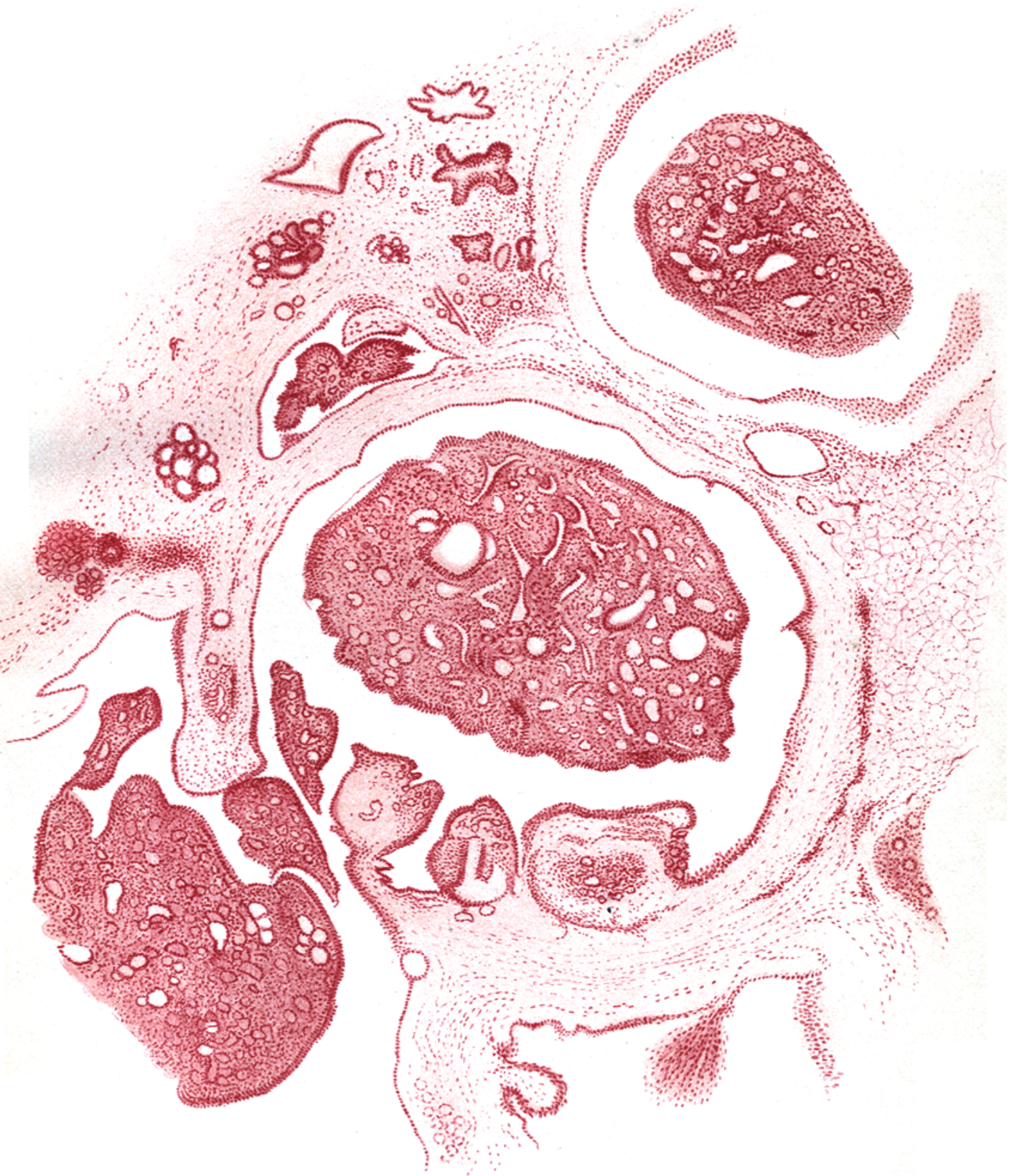

